\title{
Wavelet transform based fault detector for protection of series capacitor compensated three phase transmission line
}

\author{
Gaurav Kapoor \\ Department of Electrical Engineering, Modi Institute of Technology, Kota, INDIA \\ Corresponding Author: e-mail: gaurav.kapoor019@gmail.com, Mobile: +91-9166868988
}

\begin{abstract}
This paper proposes wavelet transform based fault detector for the protection of series capacitor compensated three phase transmission line. Three phase current measured at the relay location of a transmission line is processed using wavelet transform with daubechies-4 mother wavelet. Numerous fault situations are studied to check the performance of the proposed fault detector. To assess the performance of proposed fault detector, various fault parameters such as fault inception time, fault resistance, fault location, fault type and ground resistance are varied. Simulation results exemplify the accurateness and effectiveness of the proposed fault detector.
\end{abstract}

Keywords: Wavelet transform, series compensated transmission line protection and fault detection.

DOI: http://dx.doi.org/10.4314/ijest.v10i4.4

\section{Introduction}

Between the different components of power transmission and distribution system, protection of transmission lines is very compulsory because the transmission lines are the most expected to experience faults. Detection of fault in transmission lines is essential to provide proficient and consistent power flow. Many researchers did detection and classification of transmission line faults using various techniques. In recent times, the application of wavelet transform has been effectively tested by many researchers for the transmission line protection. Series compensation of transmission line by using series capacitors not only compensate the inductive reactance of transmission line but also enhances the capability of power transfer of transmission line.

Among various methods reported, Hilbert huang transform and machines learning techniques has been used for the detection and classification of micro-grid faults (Mishra and Rout, 2018). Artificial neural network has been used to locate multi-location faults on series capacitor compensated double circuit transmission line (Swetapadma and Yadav, 2018). A combination of wavelet transform, adaptive particle swarm optimization and artificial neural network has been used for the protection of six phase transmission line (Shukla et al., 2018). Wavelet singular entropy in combination with fuzzy system is used for the detection and classification of distributed generation connected distribution line faults (Rangari and Yadav, 2017). A combination of discrete wavelet transform and back propagation neural network has been used for the detection, classification and location estimation of HVAC transmission line faults (Saha et al., 2016). Different techniques such as wavelet transform, travelling wave and support vector machines has been used by the researchers for high impedance fault detection (Bhongade and Golhani, 2016). Probabilistic neural network based approach is described for fault classification of multi terminal series compensated transmission line (Raval and Pandya, 2016). Harmony search algorithm based approach is proposed for the classification of transmission line faults (Abdelgayed et al., 2016). Effective location of faults in three terminal transmission line using the combination of Hilbert huang transform and discrete wavelet transform is introduced (Moravej et al., 2015). A combination of discrete wavelet transform and artificial neural network has been used for the detection, classification and location of faults in parallel transmission lines (Swetapadma and Yadav, 2015). A fault location scheme which uses unsynchronized current and voltage signals for the protection of series compensated double circuit transmission line has been introduced by the researchers (Kang et al., 2015). Wavelet based 
single ended fault location technique for the protection of double circuit transmission line is proposed (Xie et al., 2013). A directional relaying technique has been presented for the protection of TCSC connected three phase transmission line (Jena and Pradhan, 2013). A comparison of single and modular ANN based fault detection and classification techniques for double circuit transmission line protection is described (Yadav, 2012). A combination of wavelet transform and artificial intelligence has been used for fault detection and classification of EHV transmission line (Chen and Aggarwal, 2012). ANN based approach is introduced for the detection and classification of inter-circuit and cross country faults (Jain et al., 2010). A combination of wavelet transform and artificial neural network has been used for the selection of faulted phase on double circuit transmission line (Kale et al., 2009). Differential protection scheme based on wavelet transform has been introduced for the protection of tapped transmission line (Bhalja and Maheshwari, 2006). A combination of Fourier transform and wavelet transform based scheme is introduced by the researchers for the detection and classification of transmission line faults (Das et al., 2006). Wavelet transform based technique is proposed for the distance protection of transmission line (Liang and Jeyasurya, 2004). Artificial neural network based approach is proposed for the classification of double circuit transmission line faults (Khorashadi-Zadeh, 2004). A combination of wavelet transform and self organizing map neural network has been used for the location of faults on TCSC compensated transmission lines (Cheong and Aggarwal, 2004).

In this paper, wavelet transform based fault detection and faulty phase identification technique is proposed for the protection of series capacitor compensated three phase transmission lines. The proposed technique uses the samples of fault current measured at one end only. The performance of proposed technique has been tested for various fault scenarios with varying different fault parameters which has not been reported until now to the best of knowledge of the author of this research paper.

\section{Simulation Studies}

Single line diagram of proposed power transmission line model is shown in Figure 1. Power transmission line model consists of $400 \mathrm{kV}, 50 \mathrm{~Hz}$, three phase series capacitor compensated transmission line of length $200 \mathrm{~km}$. Three phase voltage source of 400 $\mathrm{kV}$ is connected to the transmission line at the sending end to bus- 1 . At the receiving end, a three phase load of $100 \mathrm{MW}$ and 100 MVAr is connected to bus-2. Three phase current is obtained from the location of the relay is processed using wavelet transform to extract various features of fault current like wavelet energy, approximate coefficients and high frequency detail coefficients at level-1. Series capacitors connected at the middle of a transmission line provides $40 \%$ compensation to the transmission line. The proposed simulation model is simulated using Simscape Power Systems toolbox of MATLAB software with varying fault type $\left(F_{t}\right)$, fault resistance $\left(R_{f}\right)$, ground resistance $\left(R_{g}\right)$, fault inception time $(F I T)$ and fault location $\left(F_{1}\right)$.

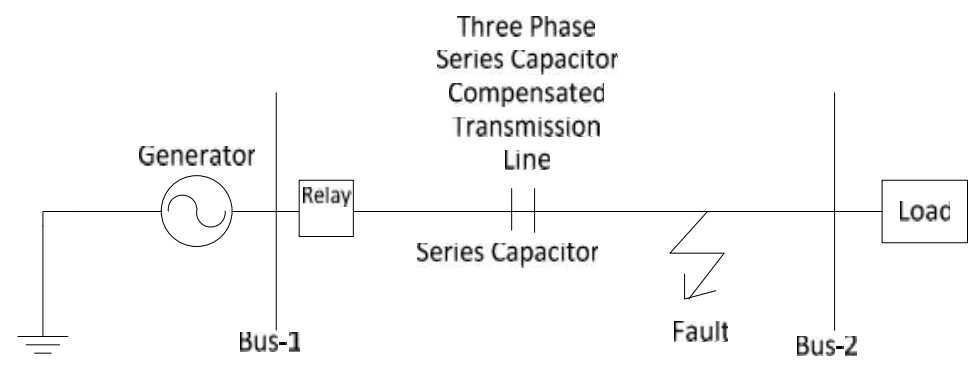

Figure 1. Schematic of proposed test system

\section{Wavelet Transform}

Wavelet transform (Jain et al., 2010; Yadav 2012) is termed as:

$$
\mathrm{W}(\mathrm{j}, \mathrm{k})=\sum_{\mathrm{j}} \sum_{\mathrm{k}} \mathrm{x}(\mathrm{k}) 2^{-\mathrm{j} / 2} \varphi\left(2^{-\mathrm{j}} \mathrm{n}-\mathrm{k}\right)
$$

where a mother wavelet is designated as $\varphi(t)$ having finite energy.

High pass filter gain after sub-sampling twice is defined as:

$$
\mathrm{y}_{\mathrm{H}}(\mathrm{k})=\sum_{\mathrm{n}} \mathrm{x}(\mathrm{n}) \mathrm{g}(2 \mathrm{k}-\mathrm{n})
$$

Low pass filter gain after sub-sampling twice is defined as:

$$
\mathrm{y}_{\mathrm{L}}(\mathrm{k})=\sum_{\mathrm{n}} \mathrm{x}(\mathrm{n}) \mathrm{h}(2 \mathrm{k}-\mathrm{n})
$$

\section{Proposed Fault Detection Scheme}

Detection of fault by using wavelet transform approach is accomplished by calculating the sum of square of high frequency detail coefficients of each phase current at level-1. The phase is called to be as faulty if the magnitude of sum of square of detail coefficients of faulted phase is found larger than the magnitude of sum of square of detail coefficients of an un-faulted phase. In 
the proposed work, 'db4' mother wavelet is used for the detection of three phase series capacitor compensated transmission line faults by wavelet decomposition of measured fault current signals captured by the relay which is connected at bus-1 of a test power system (Rangari and Yadav, 2017). The wavelet transform based fault detection scheme is illustrated in Fig. 2.

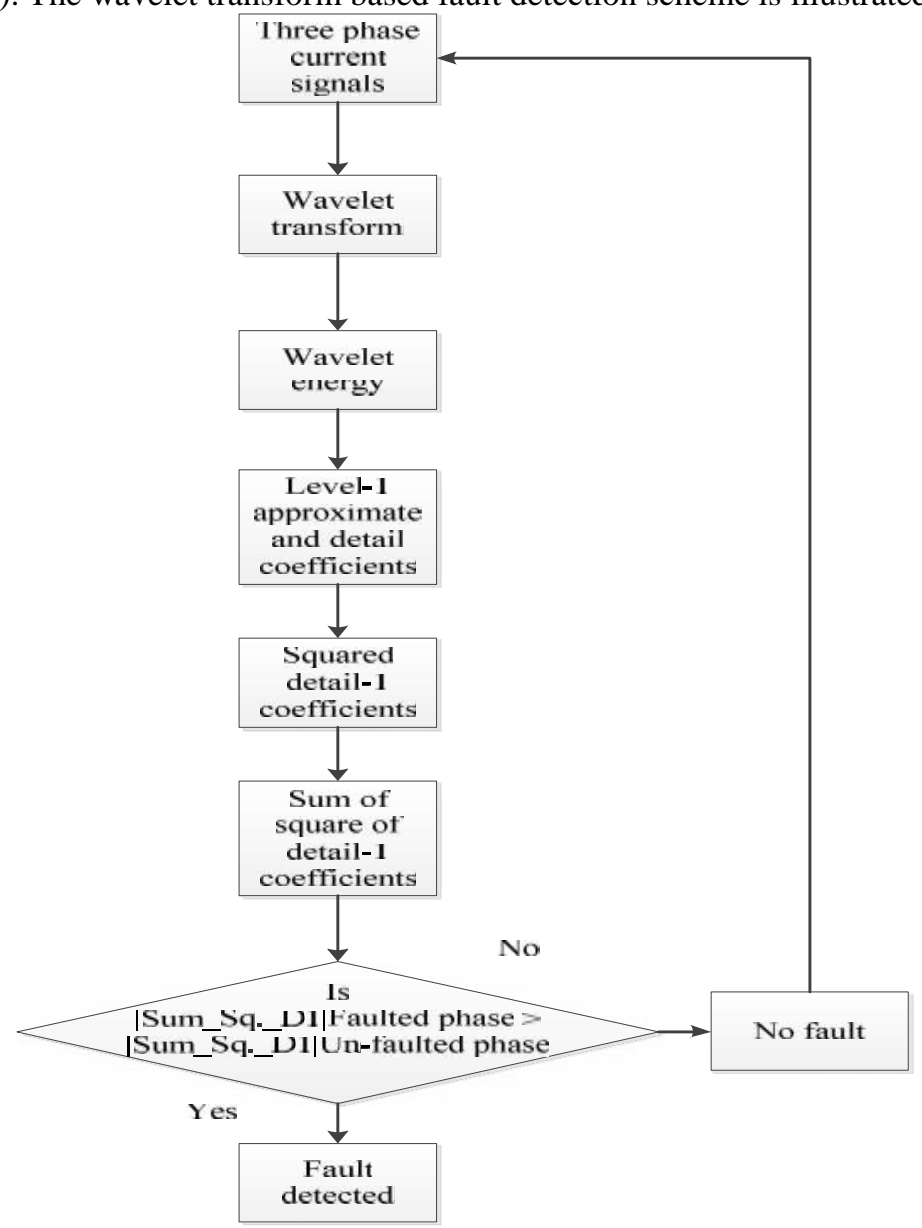

Figure 2. Wavelet Transform based fault detection scheme

\section{Simulation Results and Discussions}

The performance of the proposed technique has been tested for numerous fault situations. The proposed technique has been tested by varying different types of fault parameters. Simulation results of the proposed technique have been described in the next sub sections.

5.1 Test Results for No-Fault: By simulating the test system for no-fault, the performance of the proposed scheme is tested for healthy operation of a test system. The approximate and the high frequency detail coefficients signify the output of wavelet filter after passing the signal through it. The three phase current for the duration of no-fault is shown in Fig. 3. The approximate-1, detail-1 and squared detail-1 coefficients of phase - A, B and C for the period of no-fault are shown in Fig. 4, 5 and 6 . The performance of wavelet transform based fault detection relay is examined for no-fault operation and the test results are demonstrated in Table 1.

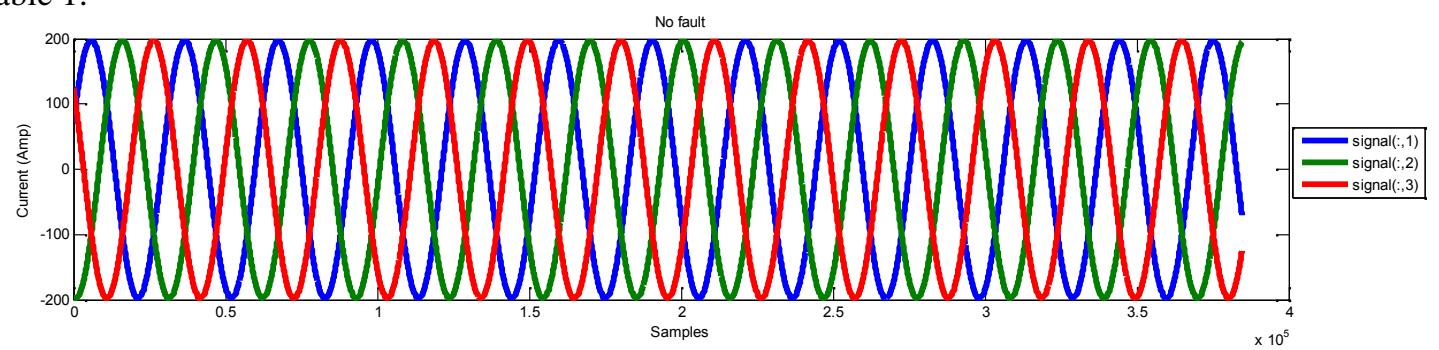

Figure 3. Three phase current during no fault 

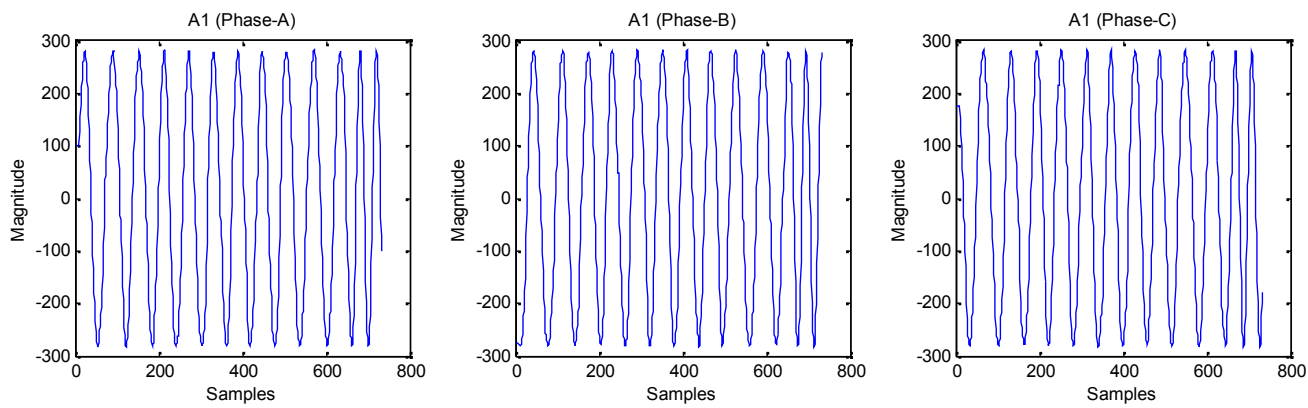

Figure 4. Approximate-1 coefficients during no fault
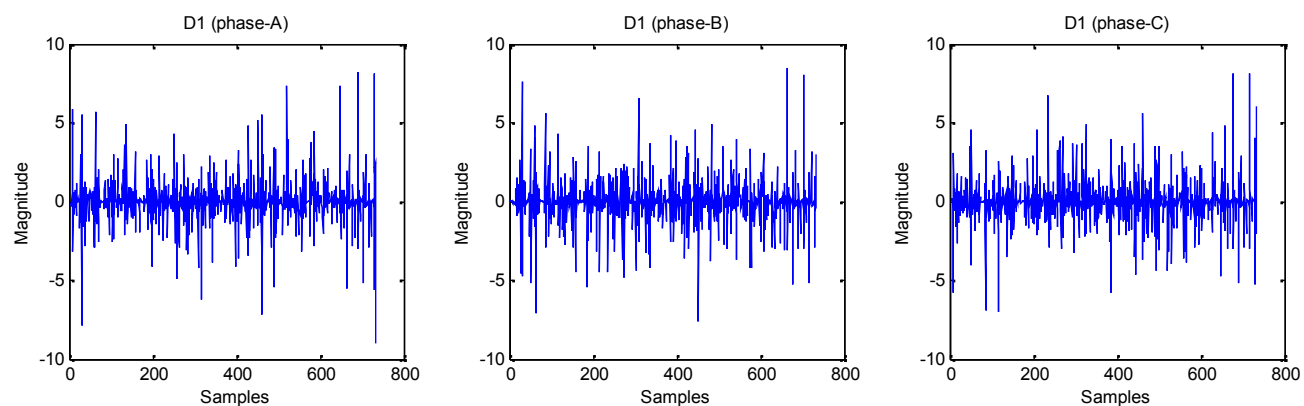

Figure 5. Detail-1 coefficients during no fault
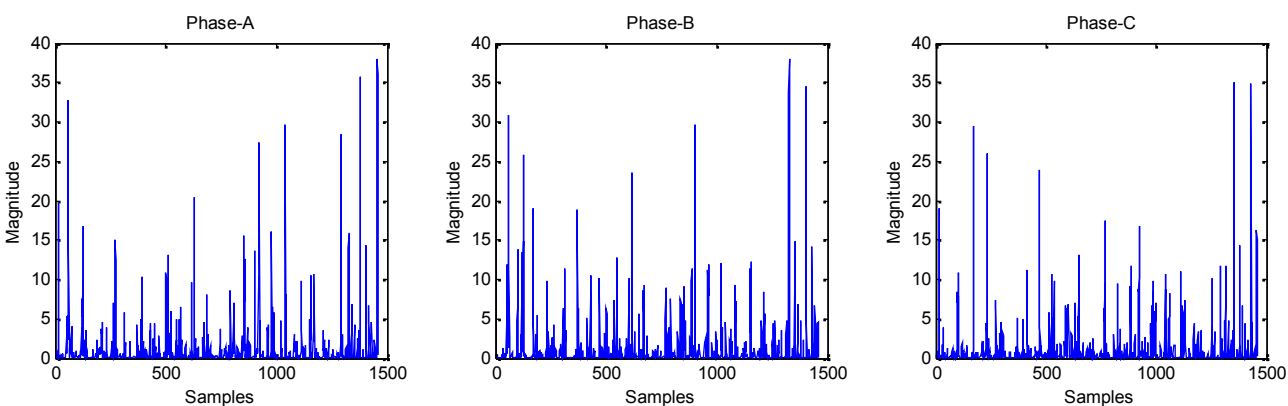

Figure 6. Squared detail-1 coefficients during no fault

Table 1. Relay output for no-fault

\begin{tabular}{|c|c|c|c|}
\hline \multirow{2}{*}{ Outputs } & A & B & C \\
\cline { 2 - 4 } & 282.3344 & 282.9103 & 282.6063 \\
\hline $\begin{array}{c}\text { Approximate } \\
\text { Coefficient }\end{array}$ & 8.2033 & 8.4728 & 8.1310 \\
\hline Detail Coefficient & 94.8766 & 97.0770 & 93.9885 \\
\hline Energy & 38.0044 & 38.0839 & 35.0419 \\
\hline $\begin{array}{c}\text { Squared Detail } \\
\text { coefficients }\end{array}$ & $1.7836^{*} 10^{\wedge} 3$ & $1.8139 * 10^{\wedge} 3$ & $1.6821 * 10^{\wedge} 3$ \\
\hline $\begin{array}{c}\text { Sum of Square of Detail } \\
\text { coefficients }\end{array}$ & & & \\
\hline
\end{tabular}

5.2 Test Results for Fault Type Variation: The performance of the proposed scheme is examined for fault type variation. The three phase current during phase-'A-g' fault at 50\% from bus-1 is shown in Fig. 7. The approximate-1, detail-1 and squared detail-1 coefficients of phase - A, B and C for the duration of phase-'A-g' fault are shown in Fig. 8, 9 and 10. The procedure of fault 
detection using wavelet transform during phase- 'A-g' fault at $50 \%$ from bus- 1 at FIT $=0.01667$ seconds with $R_{f}=0.001$ and $R_{g}$ $=0.001$ can be seen in Fig. 8-10. The performance of the proposed scheme is examined for several fault type occurring at 50\% from bus-1 with $R_{\mathrm{f}}=0.001, \mathrm{R}_{\mathrm{g}}=0.001$ and FIT $=0.01667$ seconds and the test results are depicted in Table 2-5. From Table 25 , it can be certainly seen that the magnitude of sum of square of detail-1 coefficients of faulted phase is larger than the magnitude of sum of square of detail-1 coefficients of un-faulted phase and this exemplifies that the proposed wavelet transform based fault detection scheme effectively detects the fault. Based on a variety of test results which can be seen from Table 2 to Table 5, it is established that the variation in fault type has no major effect on the performance of the relay.

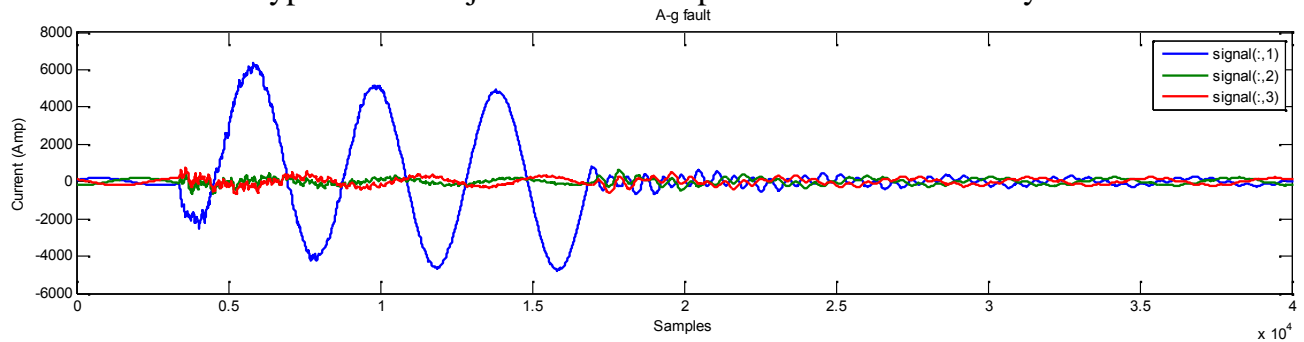

Figure 7. Three phase current during phase-'A-g' fault at 50\% from bus-1
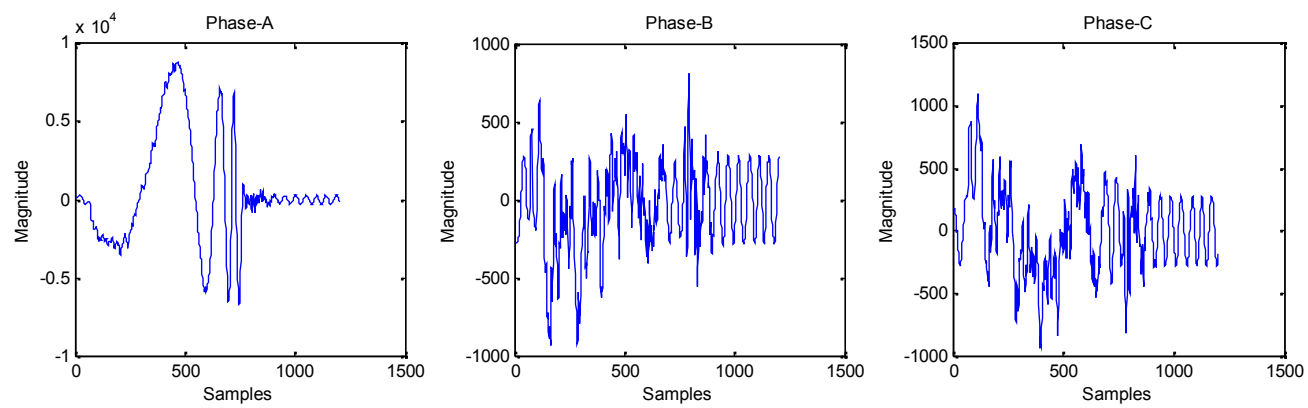

Figure 8. Approximate-1 coefficients during phase- 'A-g' fault
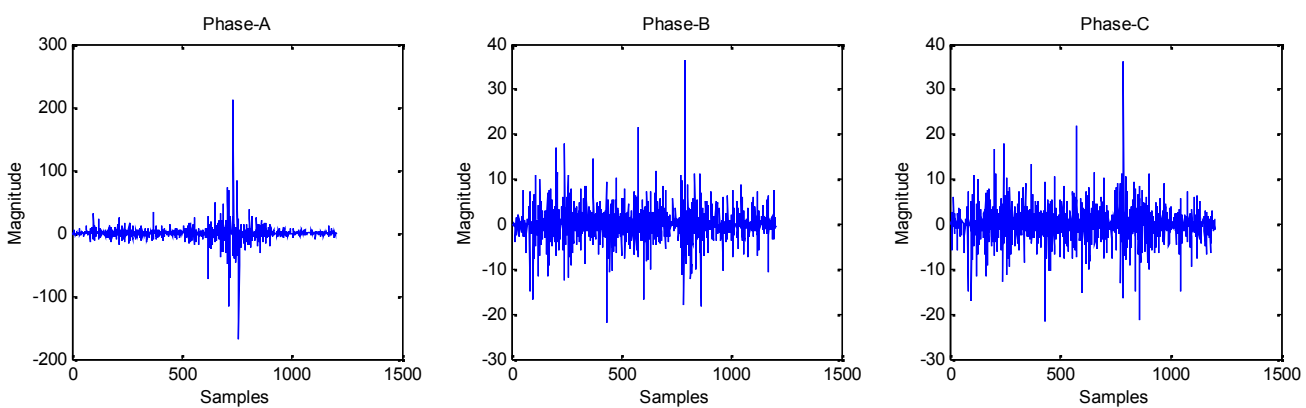

Figure 9. Detail-1 coefficients during phase- 'A-g' fault
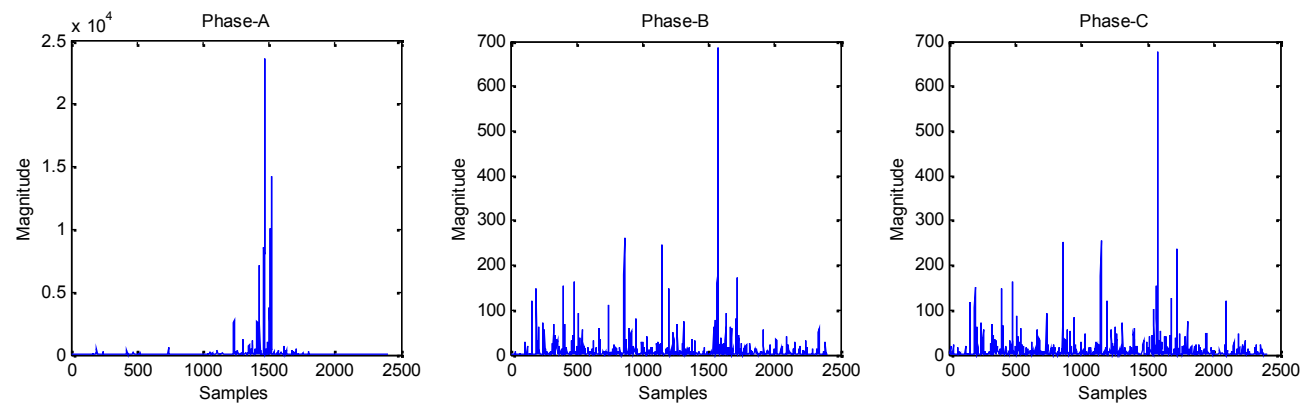

Figure 10. Squared detail-1 coefficients during phase-'A-g' fault 
Table 2. Relay output for phase-'A-g' fault at 50\% from bus-1

\begin{tabular}{|c|c|c|c|}
\hline \multirow{2}{*}{ Outputs } & A & B & C \\
\cline { 2 - 4 } & $8.8880^{*} 10^{\wedge} 3$ & 813.4495 & $1.0964 * 10^{\wedge} 3$ \\
\hline $\begin{array}{c}\text { Approximate } \\
\text { Coefficient }\end{array}$ & 212.6956 & 36.4076 & 36.1801 \\
\hline Detail Coefficient & 98.5319 & 82.3285 & 86.3756 \\
\hline Energy & $2.3609 * 10^{\wedge} 4$ & 685.3459 & 677.2337 \\
\hline $\begin{array}{c}\text { Squared Detail } \\
\text { coefficients }\end{array}$ & $2.3588 * 10^{\wedge} 5$ & $1.7150 * 10^{\wedge} 4$ & $1.7978 * 10^{\wedge} 4$ \\
\hline $\begin{array}{c}\text { Sum of Square of Detail } \\
\text { coefficients }\end{array}$ & \multicolumn{2}{|c|}{} \\
\hline \multicolumn{2}{c}{} \\
\hline
\end{tabular}

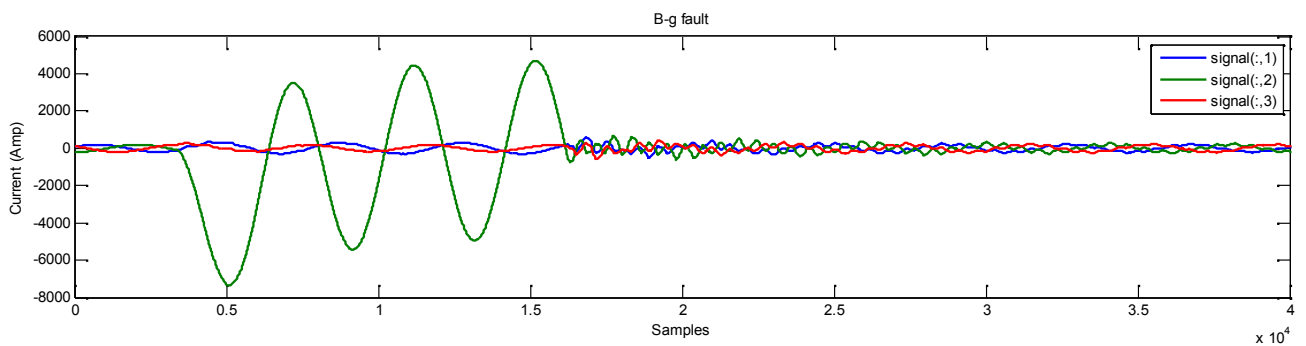

Figure 11. Three phase current during phase-'B-g' fault at 50\% from bus-1
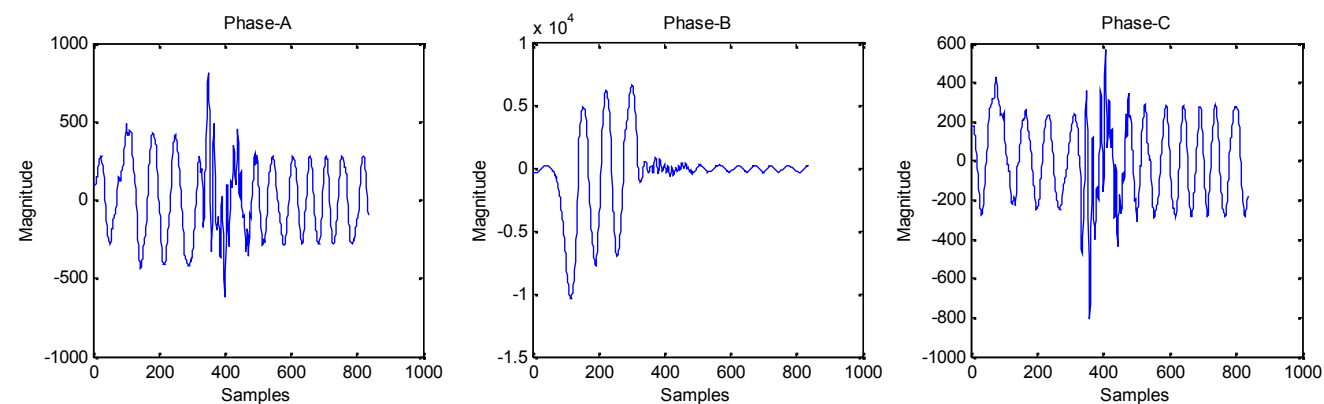

Figure 12. Approximate-1 coefficients during phase- 'B-g' fault
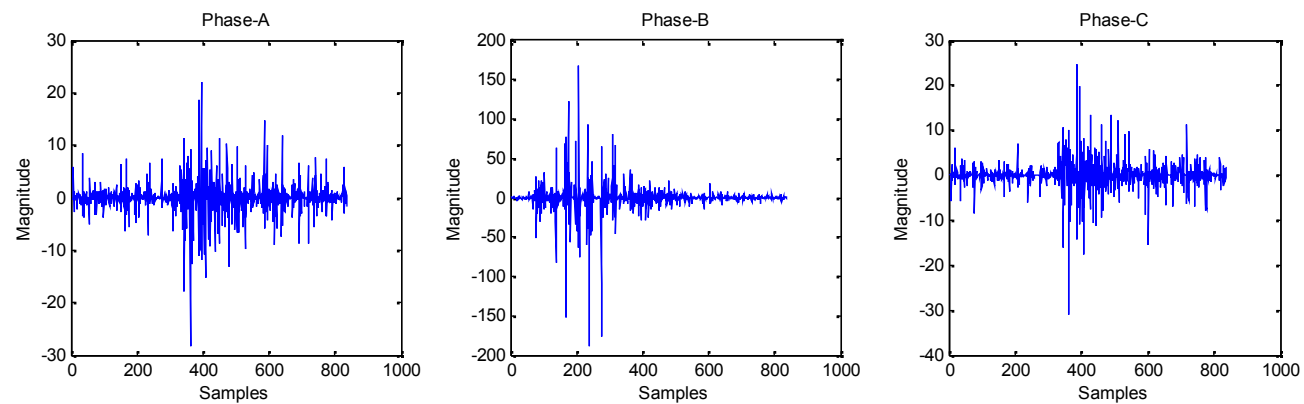

Figure 13. Detail-1 coefficients during phase- 'B-g' fault 

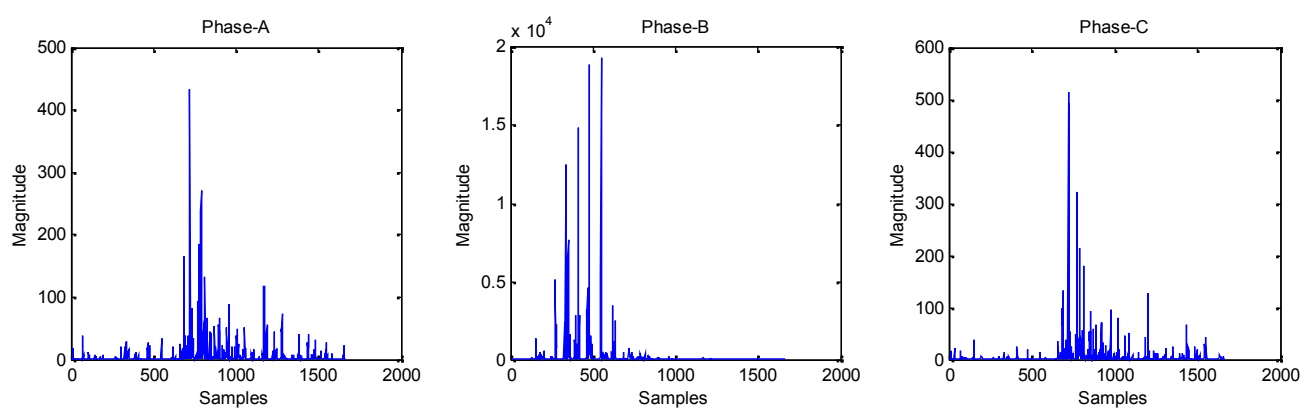

Figure 14. Squared detail-1 coefficients during phase-'B-g' fault

Table 3. Relay output for phase-'B-g' fault at $50 \%$ from bus-1

\begin{tabular}{|c|c|c|c|}
\hline \multirow{2}{*}{ Outputs } & A & B & C \\
\cline { 2 - 4 } & 808.5612 & $6.6449 * 10^{\wedge} 3$ & 569.9636 \\
\hline $\begin{array}{c}\text { Approximate } \\
\text { Coefficient }\end{array}$ & 22.1521 & 167.0900 & 24.7728 \\
\hline Detail Coefficient & 86.8379 & 98.3984 & 84.5278 \\
\hline Energy & 433.7337 & $1.9330^{*} 10^{\wedge} 4$ & 513.6563 \\
\hline $\begin{array}{c}\text { Squared Detail } \\
\text { coefficients }\end{array}$ & $9.0309 * 10^{\wedge} 3$ & $2.8314 * 10^{\wedge} 5$ & $8.9962 * 10^{\wedge} 3$ \\
\hline $\begin{array}{c}\text { Sum of Square of Detail } \\
\text { coefficients }\end{array}$ & & & \\
\hline
\end{tabular}

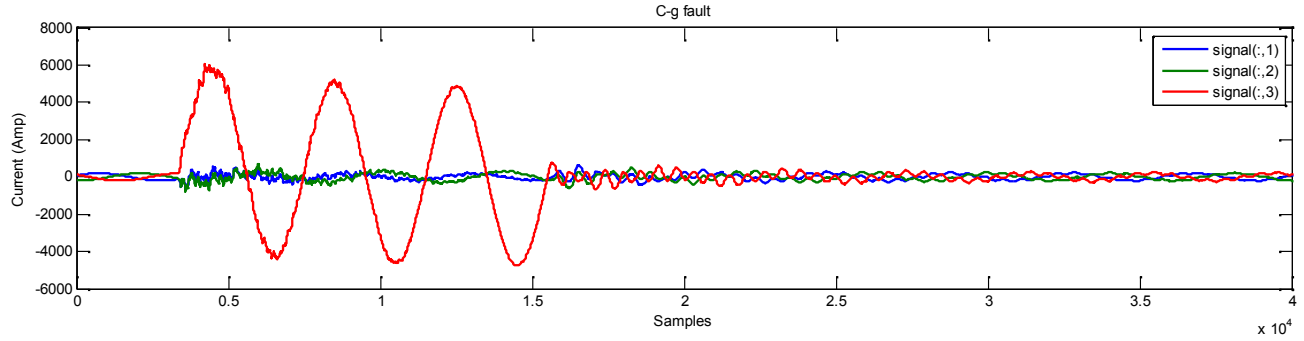

Figure 15. Three phase current during phase- 'C-g' fault at 50\% from bus-1
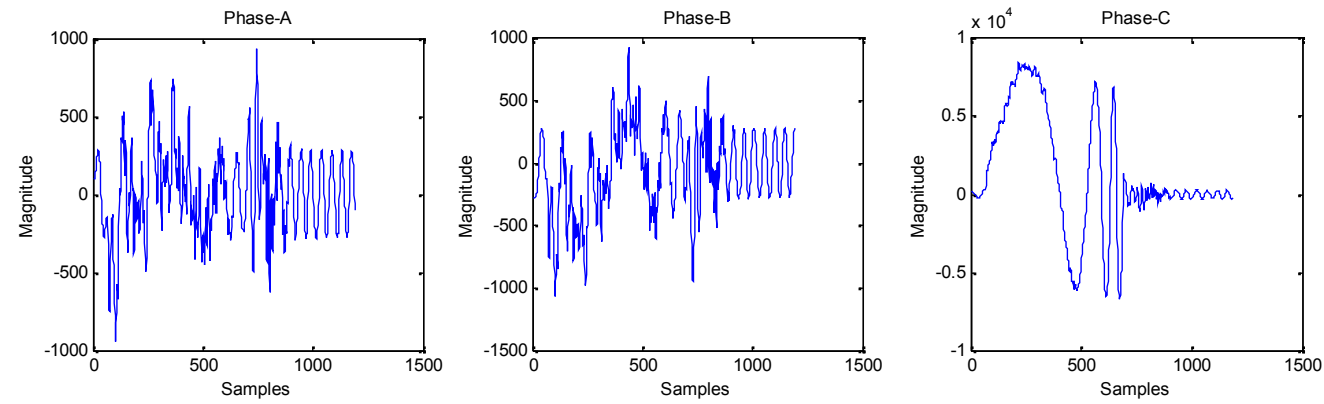

Figure 16. Approximate-1 coefficients during phase- 'C-g' fault 

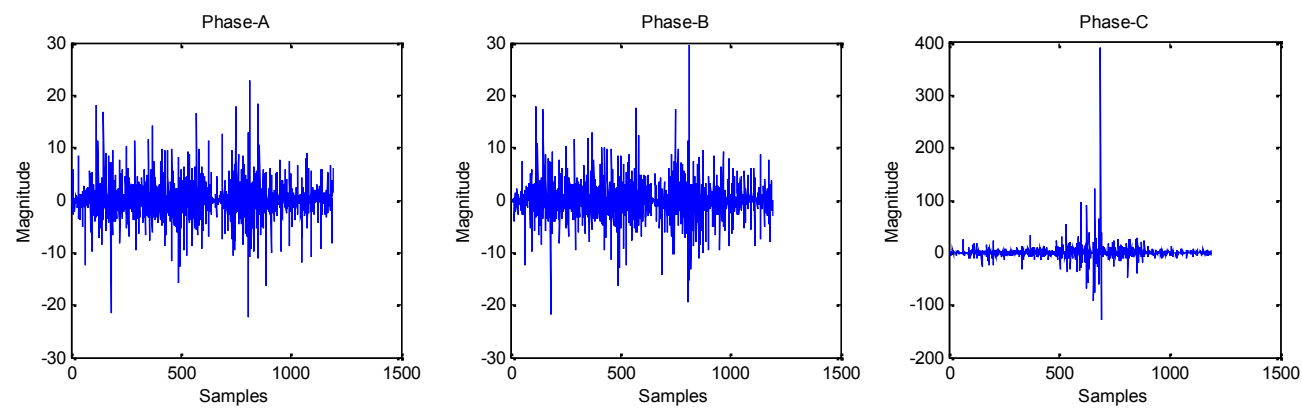

Figure 17. Detail-1 coefficients during phase- 'C-g' fault
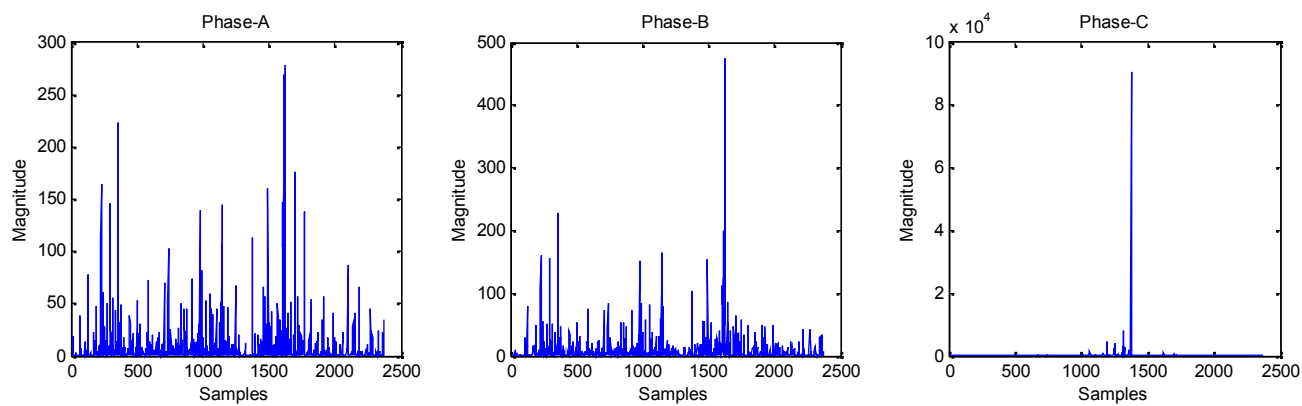

Figure 18. Squared detail-1 coefficients during phase- 'C-g' fault

Table 4. Relay output for phase-'C-g' fault at $50 \%$ from bus-1

\begin{tabular}{|c|c|c|c|}
\hline \multirow{2}{*}{ Outputs } & A & B & Chases \\
\cline { 2 - 4 } & 935.7426 & 933.5595 & $8.4723 * 10^{\wedge} 3$ \\
\hline $\begin{array}{c}\text { Approximate } \\
\text { Coefficient }\end{array}$ & 22.7084 & 29.6354 & 390.8781 \\
\hline Detail Coefficient & 80.1632 & 86.9675 & 99.4036 \\
\hline Energy & 278.0527 & 474.1977 & $9.0563 * 10^{\wedge} 4$ \\
\hline $\begin{array}{c}\text { Squared Detail } \\
\text { coefficients }\end{array}$ & $1.7220 * 10^{\wedge} 4$ & $1.7088 * 10^{\wedge} 4$ & $3.3023 * 10^{\wedge} 5$ \\
\hline $\begin{array}{c}\text { Sum of Square of Detail } \\
\text { coefficients }\end{array}$ & & & \\
\hline
\end{tabular}

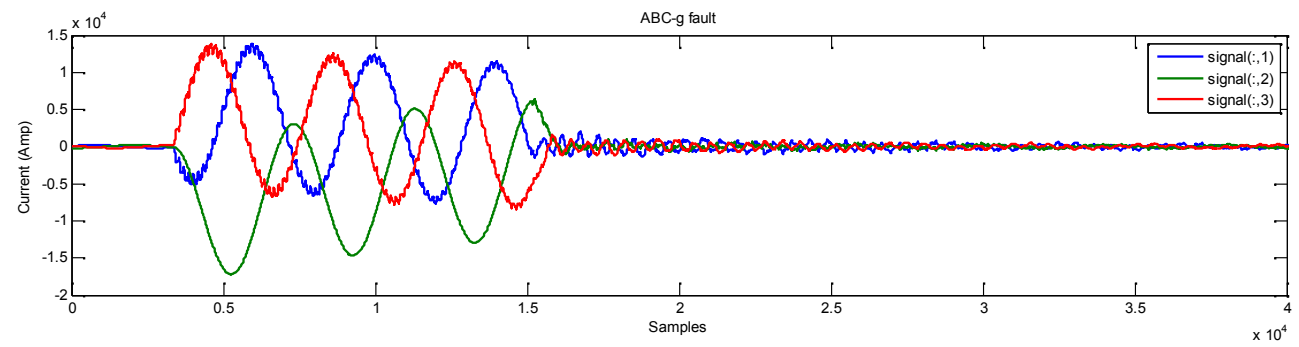

Figure 19. Three phase current during phase- 'ABC-g' fault at $50 \%$ from bus-1 

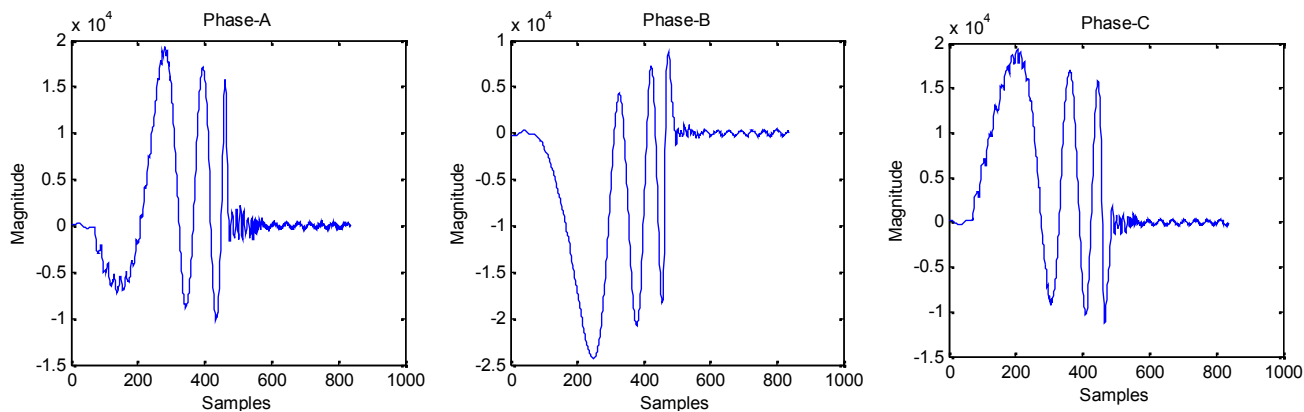

Figure 20. Approximate-1 coefficients during phase- 'ABC-g' fault
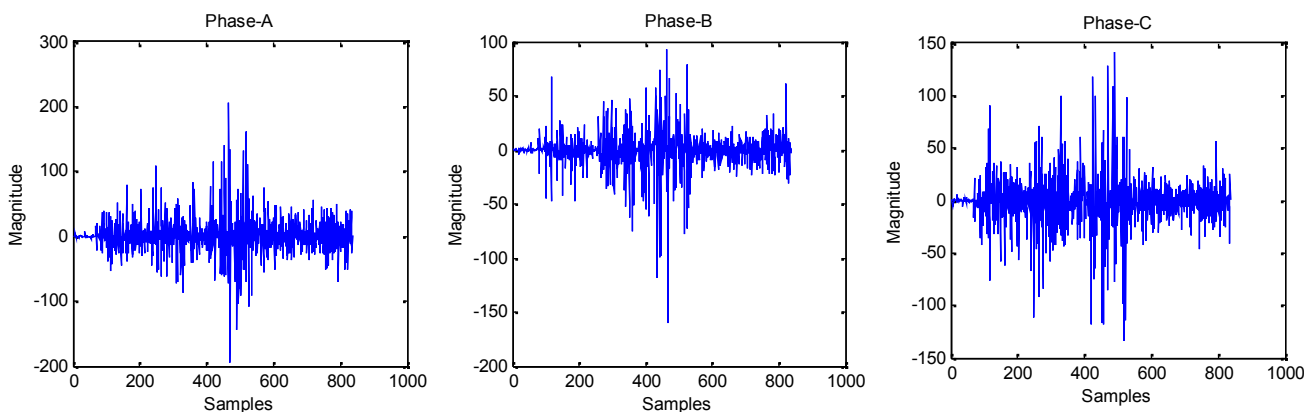

Figure 21. Detail-1 coefficients during phase- 'ABC-g' fault
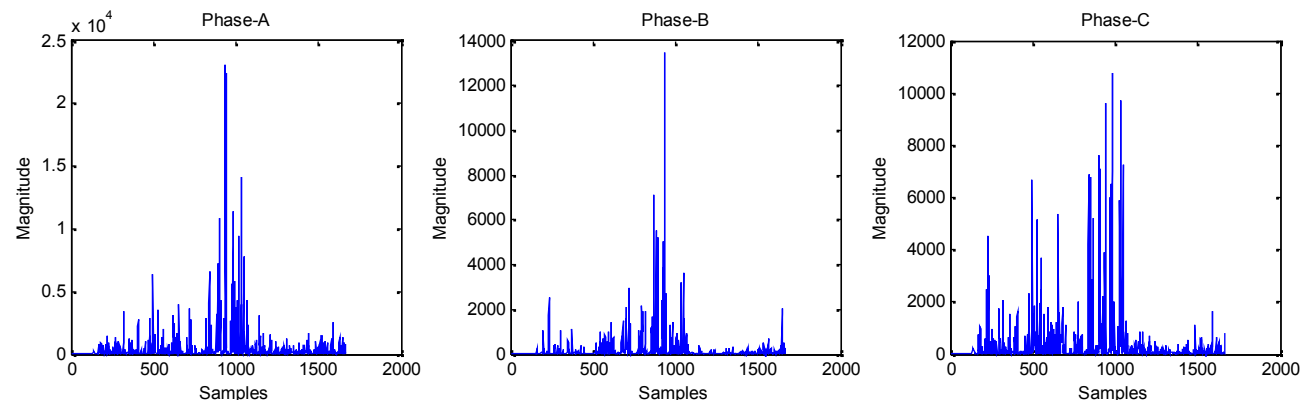

Figure 22. Squared detail-1 coefficients during phase- ‘ABC-g’ fault

Table 5. Relay output for phase-'ABC-g' fault at 50\% from bus-1

\begin{tabular}{|c|c|c|c|}
\hline \multirow{2}{*}{ Outputs } & A & B & C \\
\cline { 2 - 4 } & $1.9346 * 10^{\wedge} 4$ & $8.7384 * 10^{\wedge} 3$ & $1.9298 * 10^{\wedge} 4$ \\
\hline $\begin{array}{c}\text { Approximate } \\
\text { Coefficient }\end{array}$ & 206.4917 & 93.6656 & 141.0414 \\
\hline Detail Coefficient & 99.1818 & 99.5520 & 98.7278 \\
\hline Energy & $2.3088 * 10^{\wedge} 4$ & $1.3456 * 10^{\wedge} 4$ & $1.0774 * 10^{\wedge} 4$ \\
\hline $\begin{array}{c}\text { Squared Detail } \\
\text { coefficients }\end{array}$ & $7.7360^{*} 10^{\wedge} 5$ & $3.1011 * 10^{\wedge} 5$ & $5.6033 * 10^{\wedge} 5$ \\
\hline $\begin{array}{c}\text { Sum of Square of Detail } \\
\text { coefficients }\end{array}$ & \multicolumn{2}{|c|}{} \\
\hline
\end{tabular}

5.3 Test Results for Fault Location Variation: By simulating the test system for various fault cases at different locations, the performance of the proposed scheme is tested for fault location variation. The three phase current during phase- 'A-g' fault at $10 \%$ from bus-1 at FIT $=0.01667$ seconds is illustrated in Fig. 23. The approximate-1, detail-1 and squared detail- 1 coefficients of 
phase - A, B and C for the duration of phase-'A-g' fault at 10\% from bus-1 are shown in Fig. 24, 25 and 26. The method of fault detection using wavelet transform during phase- 'A-g' fault at $10 \%$ from bus- 1 at FIT $=0.01667$ seconds with $R_{f}=0.001$ and $R_{g}$ $=0.001$ can be seen in Fig. 24-26. The performance of the proposed scheme is observed for numerous fault locations from bus- 1 with $R_{f}=0.001, R_{g}=0.001$ and FIT $=0.01667$ seconds and the test results are depicted in Table 6 to Table 7. From Table 6-7, it can be definitely seen that the magnitude of sum of square of detail-1 coefficients of faulted phase is larger than the magnitude of sum of square of detail-1 coefficients of un-faulted phase and this illustrates that the proposed wavelet transform based fault detection scheme efficiently detects the fault. Based on a variety of test results which can be seen from Table 6-7 it is recognized that the variation in fault location has no major effect on the relay performance.

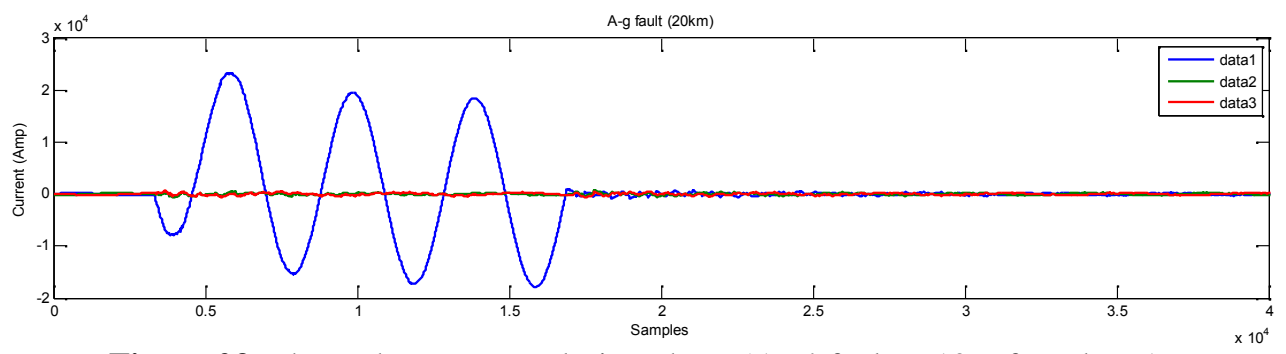

Figure 23. Three phase current during phase-'A-g' fault at $10 \%$ from bus-1
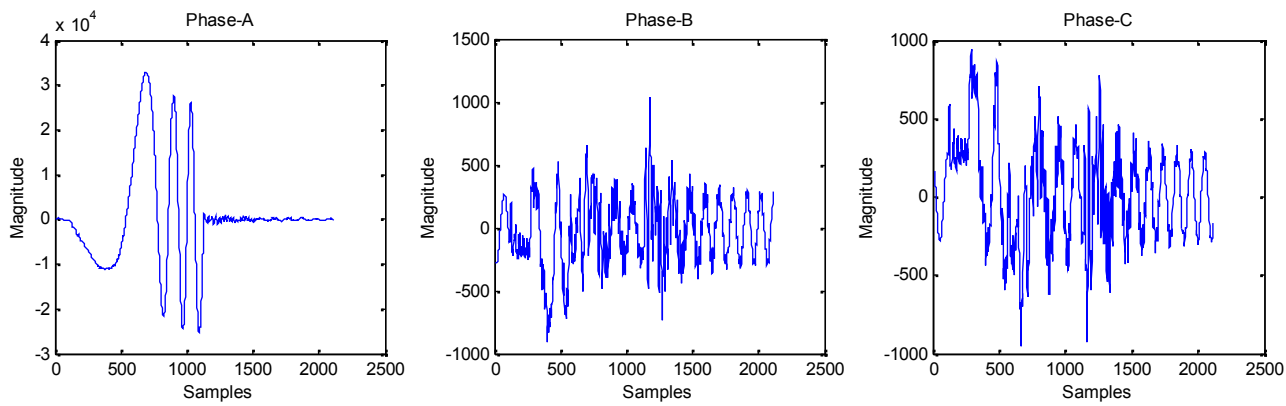

Figure 24. Approximate-1 coefficients during phase- 'A-g' fault at $10 \%$ from bus-1
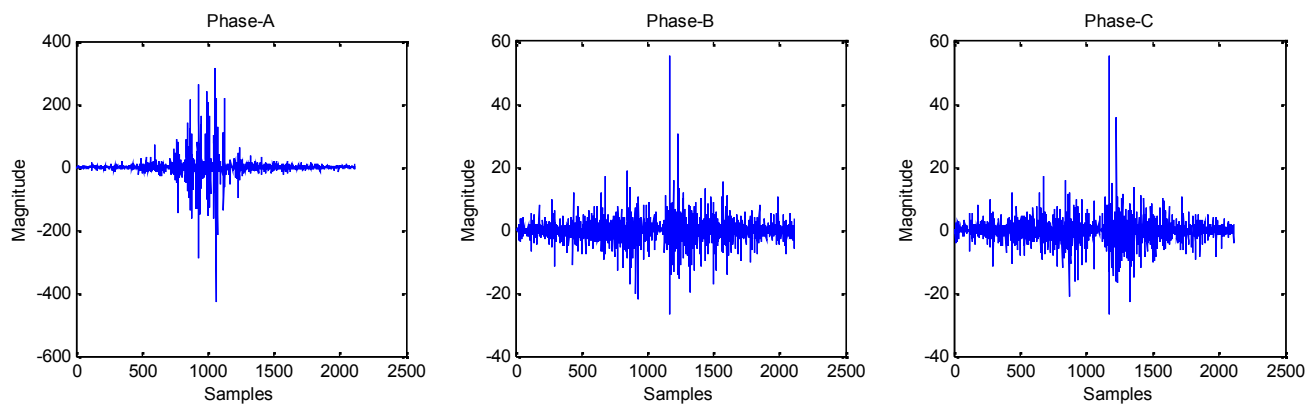

Figure 25. Detail-1 coefficients during phase- 'A-g' fault at 10\% from bus-1
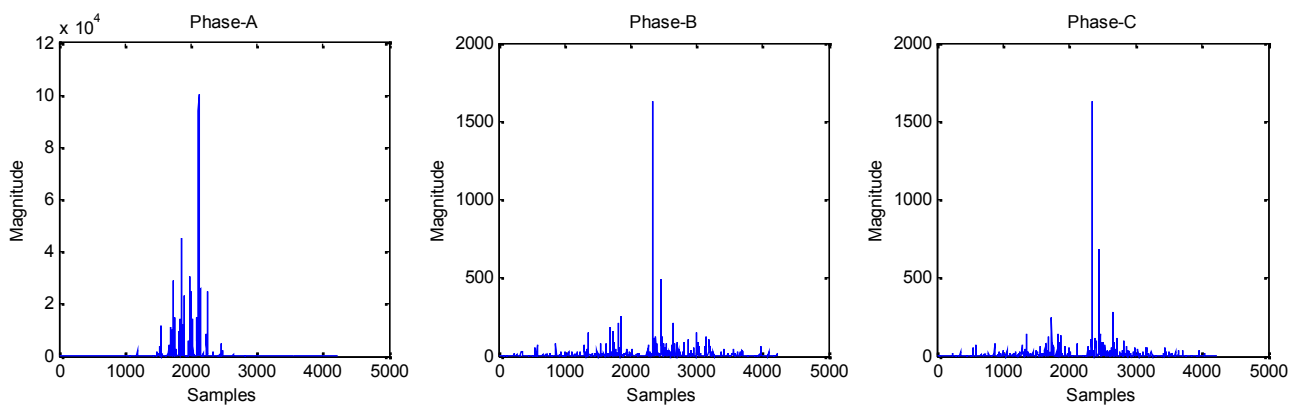

Figure 26. Squared detail-1 coefficients during phase-'A-g' fault at 10\% from bus-1 
Table 6. Relay output for phase-'A-g' fault at $10 \%$ from bus-1

\begin{tabular}{|c|c|c|c|}
\hline \multirow{2}{*}{ Outputs } & A & B & C \\
\cline { 2 - 4 } & $3.2819 * 10^{\wedge} 4$ & $1.0469 * 10^{\wedge} 3$ & 945.3910 \\
\hline $\begin{array}{c}\text { Approximate } \\
\text { Coefficient }\end{array}$ & 315.8240 & 55.3532 & 55.2580 \\
\hline Detail Coefficient & 99.9334 & 87.3004 & 90.1029 \\
\hline Energy & $1.0027 * 10^{\wedge} 5$ & $1.6316^{*} 10^{\wedge} 3$ & $1.6320^{*} 10^{\wedge} 3$ \\
\hline $\begin{array}{c}\text { Squared Detail } \\
\text { coefficients }\end{array}$ & $1.9201 * 10^{\wedge} 6$ & $2.7409 * 10^{\wedge} 4$ & $2.6168 * 10^{\wedge} 4$ \\
\hline $\begin{array}{c}\text { Sum of Square of Detail } \\
\text { coefficients }\end{array}$ & & & \\
\hline
\end{tabular}

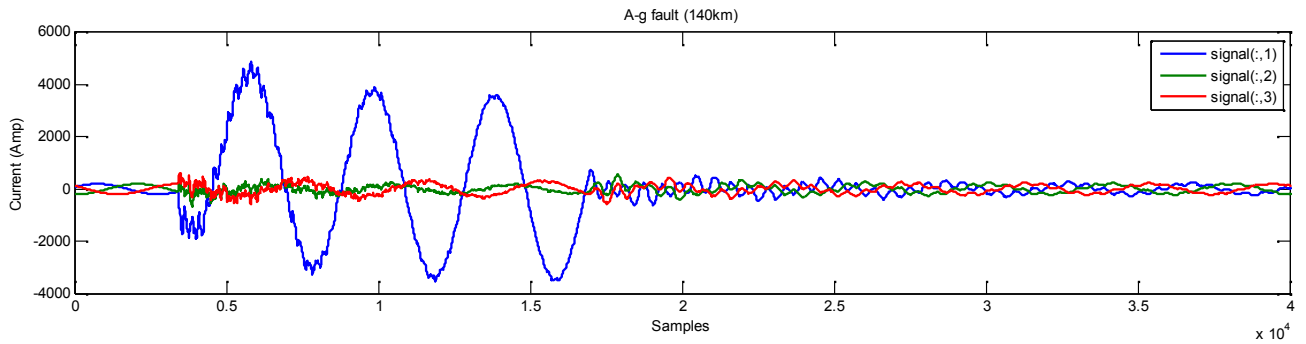

Figure 27. Three phase current during phase-'A-g' fault at 70\% from bus-1
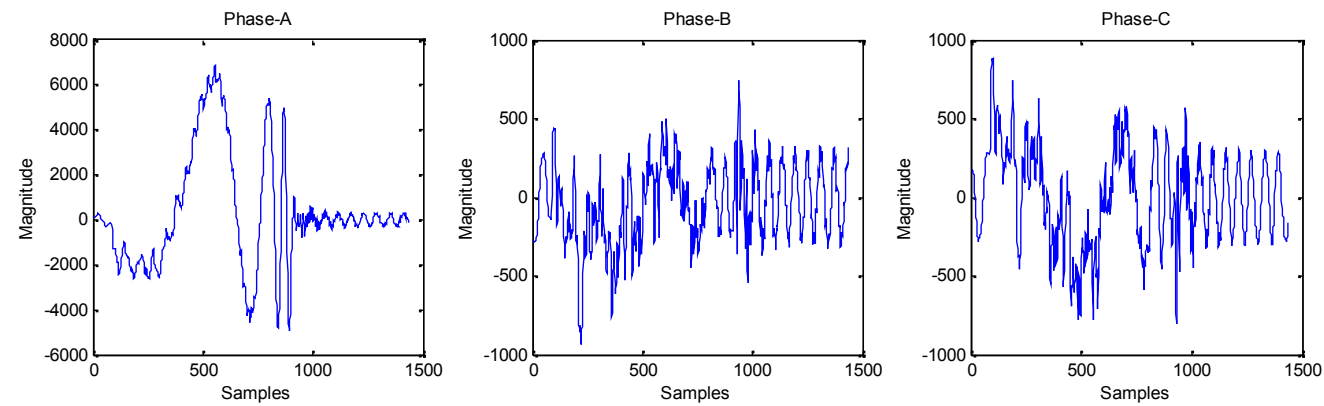

Figure 28. Approximate-1 coefficients during phase- 'A-g' fault at $70 \%$ from bus-1
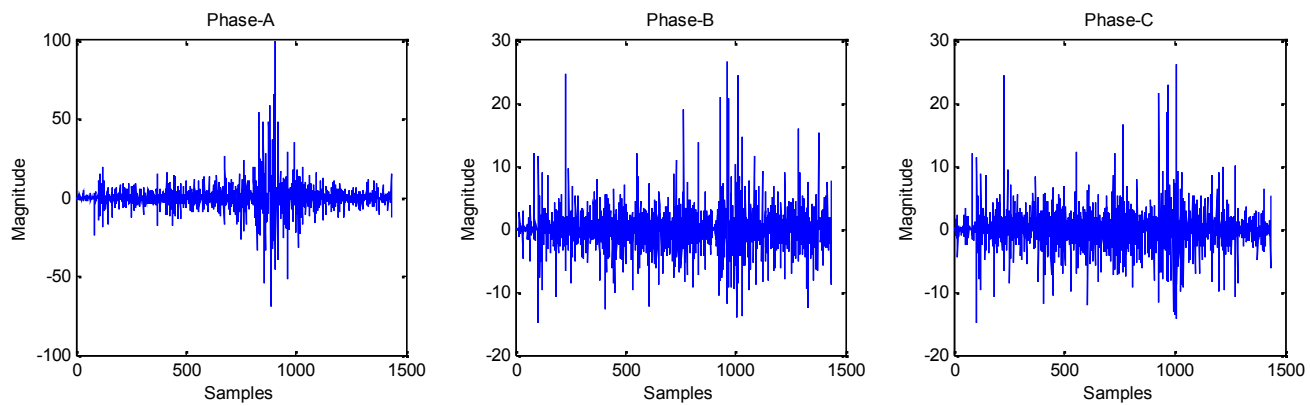

Figure 29. Detail-1 coefficients during phase- 'A-g' fault at $70 \%$ from bus-1 

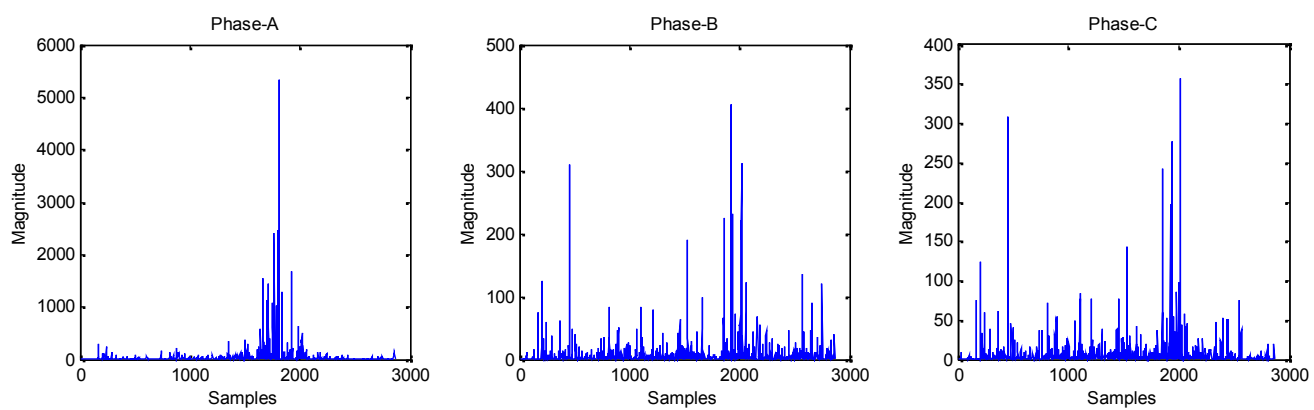

Figure 30. Squared detail-1 coefficients during phase- 'A-g' fault at $70 \%$ from bus-1

Table 7. Relay output for phase-'A-g' fault at 70\% from bus-1

\begin{tabular}{|c|c|c|c|}
\hline \multirow{2}{*}{ Outputs } & A & B & C \\
\cline { 2 - 4 } & $6.8549^{*} 10^{\wedge} 3$ & 739.6455 & 882.2599 \\
\hline $\begin{array}{c}\text { Approximate } \\
\text { Coefficient }\end{array}$ & 99.2028 & 26.5430 & 26.1155 \\
\hline $\begin{array}{c}\text { Detail Coefficient } \\
\text { Energy }\end{array}$ & 99.0121 & 85.4252 & 89.1032 \\
\hline $\begin{array}{c}\text { Squared Detail } \\
\text { coefficients }\end{array}$ & $5.3371 * 10^{\wedge} 3$ & 404.4168 & 357.7821 \\
\hline $\begin{array}{c}\text { Sum of Square of Detail } \\
\text { coefficients }\end{array}$ & $1.0410^{*} 10^{\wedge} 5$ & $1.8477^{*} 10^{\wedge} 4$ & $1.6429 * 10^{\wedge} 4$ \\
\hline
\end{tabular}

5.4 Test Results for Fault Resistance Variation: Simulation studies are conducted to examine the performance of the proposed scheme for fault resistance variation. The three phase current during phase-'AB-g' fault at $50 \%$ from bus-1 with $R_{f}=20$ is shown in Fig. 31. The approximate-1, detail-1 and squared detail-1 coefficients of phase - A, B and C for the period of phase- $\mathrm{AB}$ g' fault are shown in Fig. 32, 33 and 34. The method of fault detection using wavelet transform during phase- 'AB-g' fault at 50\% from bus- 1 at FIT $=0.01667$ seconds with $R_{f}=20$ and $R_{g}=0.001$ can be seen in Fig. 32-34. The performance of the proposed scheme is tested for various values fault resistances during phase- $A B$-g' fault at $50 \%$ from bus-1 and the test results for $\mathrm{R}_{\mathrm{f}}=20$ and 70 can be depicted in Table 8 to Table 9. From Table 8-9, it can be definitely seen that the magnitude of sum of square of detail-1 coefficients of faulted phase is larger than the magnitude of sum of square of detail-1 coefficients of un-faulted phase and this exemplifies that the proposed wavelet transform based fault detection scheme effectively detects the fault. Based on a variety of simulation results which can be seen from Table 8 to Table 9, it is established that the fault resistance variation has no major effect on the performance of the relay.

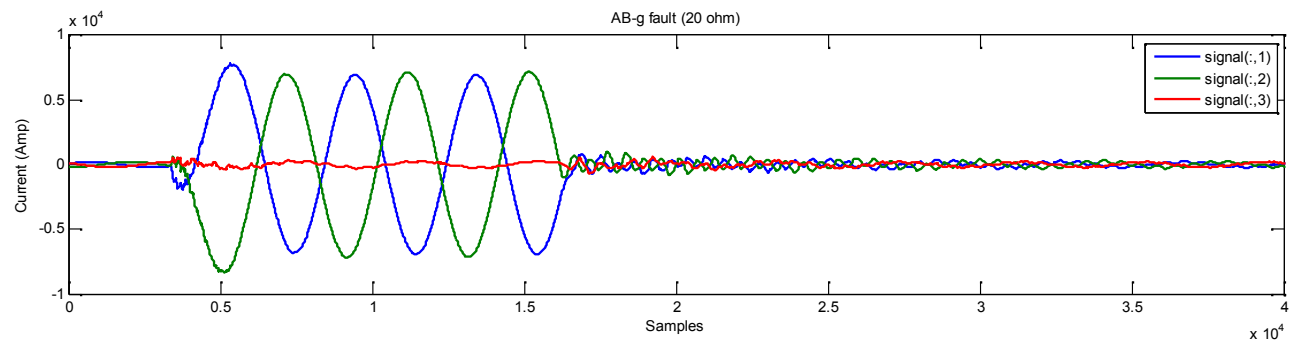

Figure 31. Three phase current during phase-'AB-g' fault at $50 \%$ from bus-1 with $R_{f}=20$ 

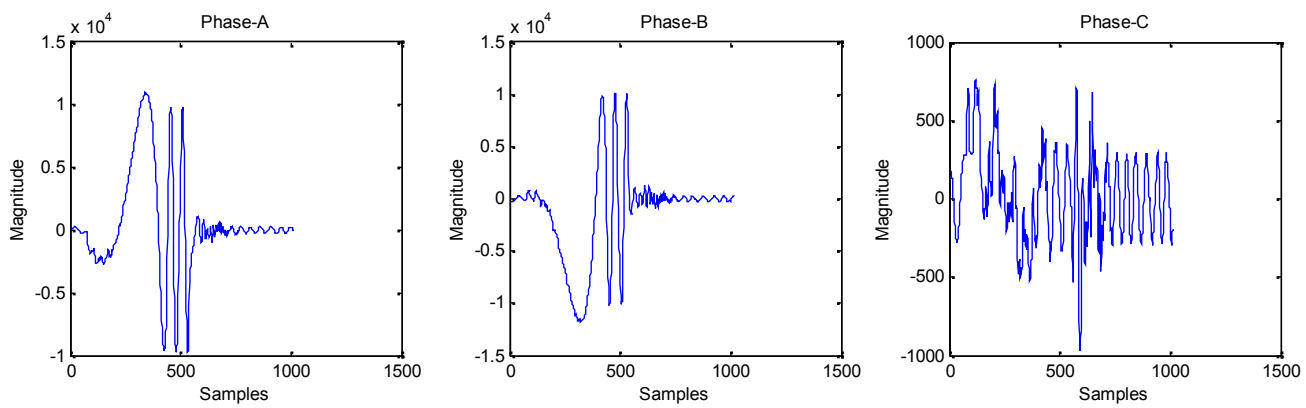

Figure 32. Approximate-1 coefficients during phase- 'AB-g' fault at $50 \%$ from bus- 1 with $\mathrm{R}_{\mathrm{f}}=20$
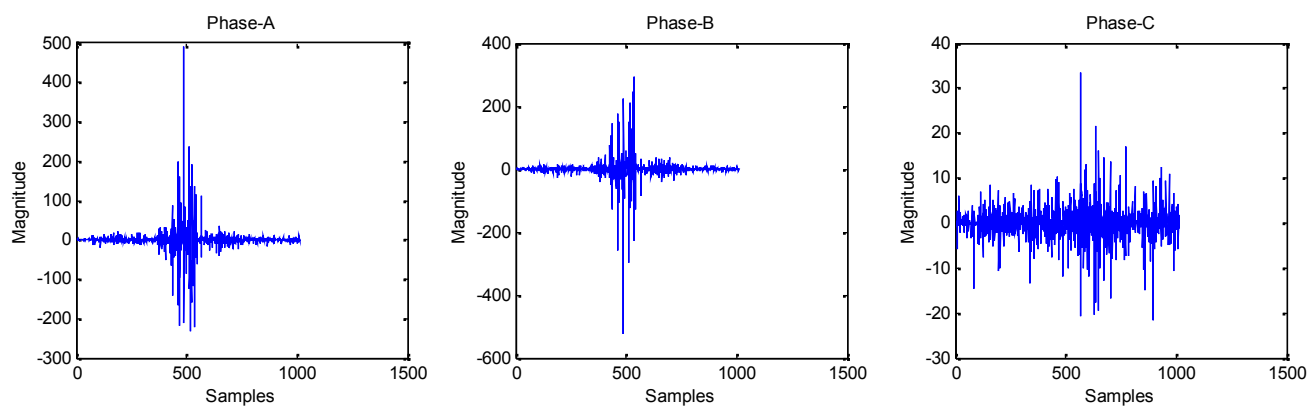

Figure 33. Detail-1 coefficients during phase- 'AB-g' fault at $50 \%$ from bus- 1 with $\mathrm{R}_{\mathrm{f}}=20$
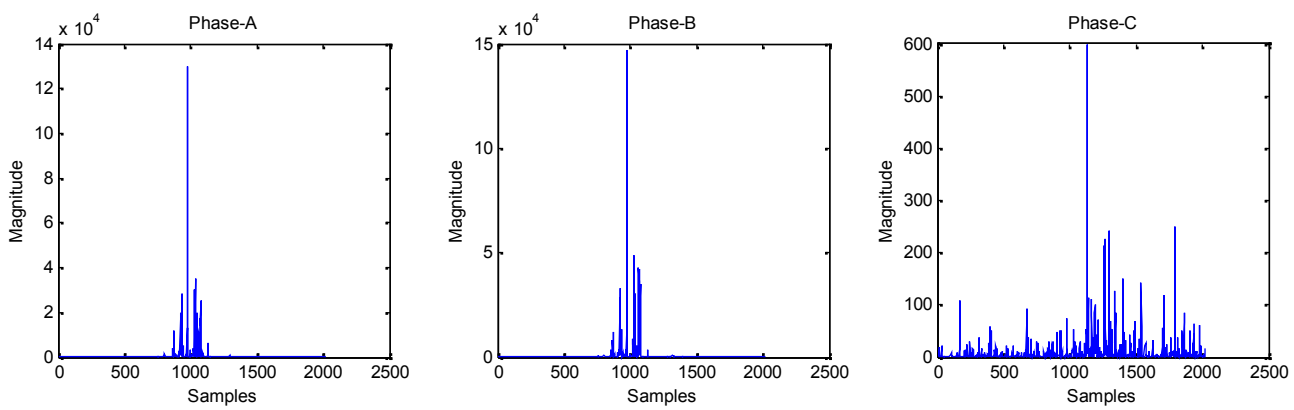

Figure 34. Squared detail-1 coefficients during phase- 'AB-g' fault at $50 \%$ from bus- 1 with $R_{f}=20$

Table 8. Relay output for phase-'AB-g' fault at $50 \%$ from bus- 1 with $\mathrm{R}_{\mathrm{f}}=20$

\begin{tabular}{|c|c|c|c|}
\hline \multirow{2}{*}{ Outputs } & A & B & C \\
\cline { 2 - 4 } & $1.0994 * 10^{\wedge} 4$ & $1.0090^{*} 10^{\wedge} 4$ & 761.8650 \\
\hline $\begin{array}{c}\text { Approximate } \\
\text { Coefficient }\end{array}$ & 492.2501 & 295.2893 & 33.4924 \\
\hline Detail Coefficient & 97.5004 & 97.8964 & 80.6305 \\
\hline Energy & $1.2996^{*} 10^{\wedge} 5$ & $1.4679^{*} 10^{\wedge} 5$ & 598.4838 \\
\hline $\begin{array}{c}\text { Squared Detail } \\
\text { coefficients }\end{array}$ & $1.0396 * 10^{\wedge} 6$ & $1.2425^{*} 10^{\wedge} 6$ & $1.6042^{*} 10^{\wedge} 4$ \\
\hline $\begin{array}{c}\text { Sum of Square of Detail } \\
\text { coefficients }\end{array}$ & \multicolumn{2}{|c|}{} \\
\hline
\end{tabular}




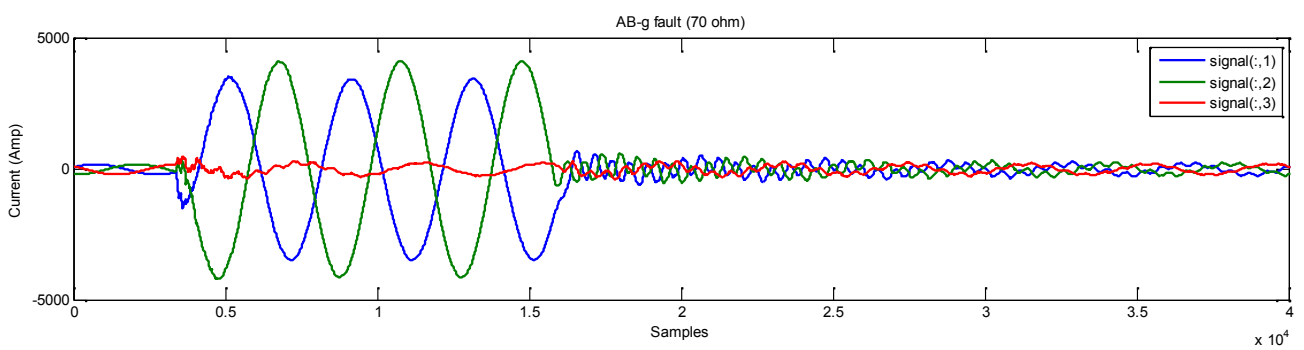

Figure 35. Three phase current during phase-'AB-g' fault at $50 \%$ from bus- 1 with $R_{f}=70^{\times 10^{4}}$
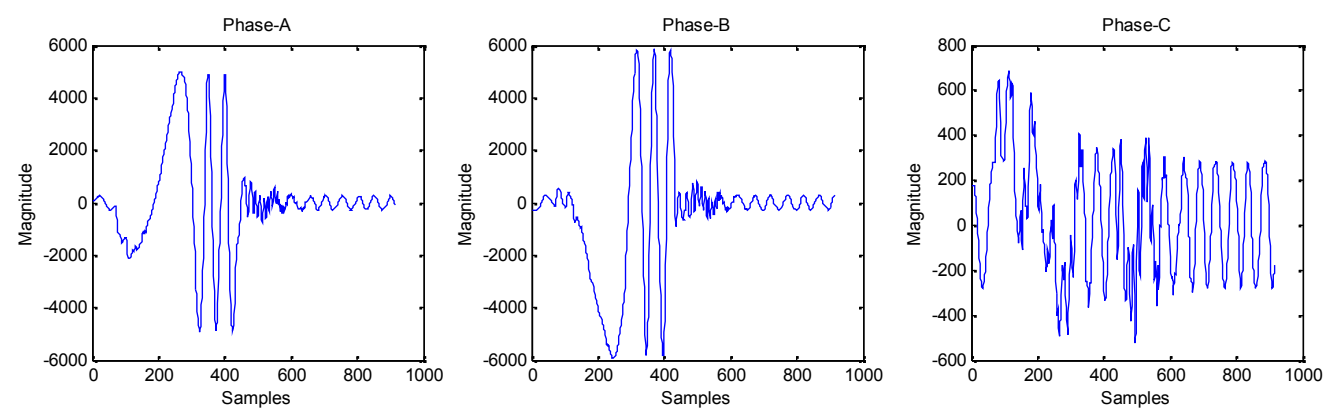

Figure 36. Approximate-1 coefficients during phase- 'AB-g' fault at $50 \%$ from bus- 1 with $\mathrm{R}_{\mathrm{f}}=70$
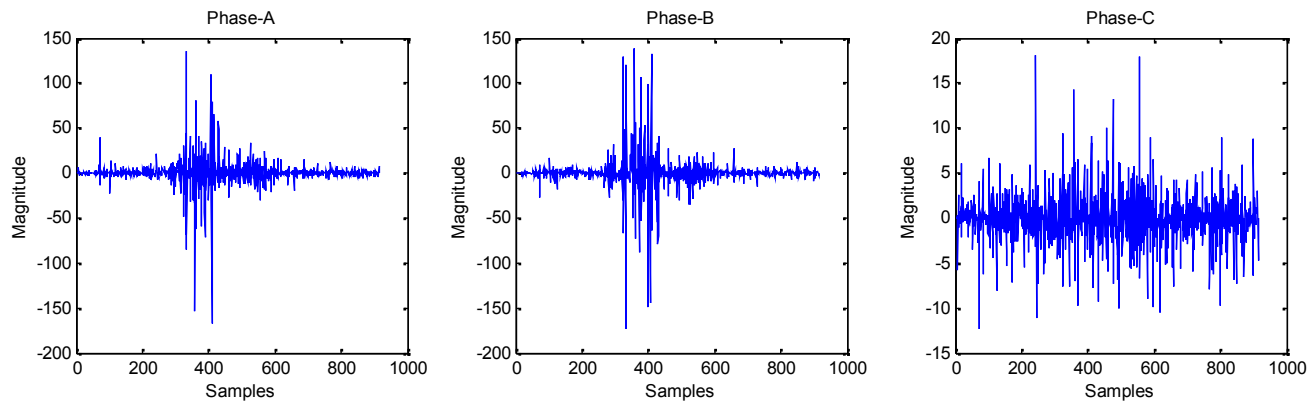

Figure 37. Detail-1 coefficients during phase- 'AB-g' fault at $50 \%$ from bus- 1 with $R_{f}=70$
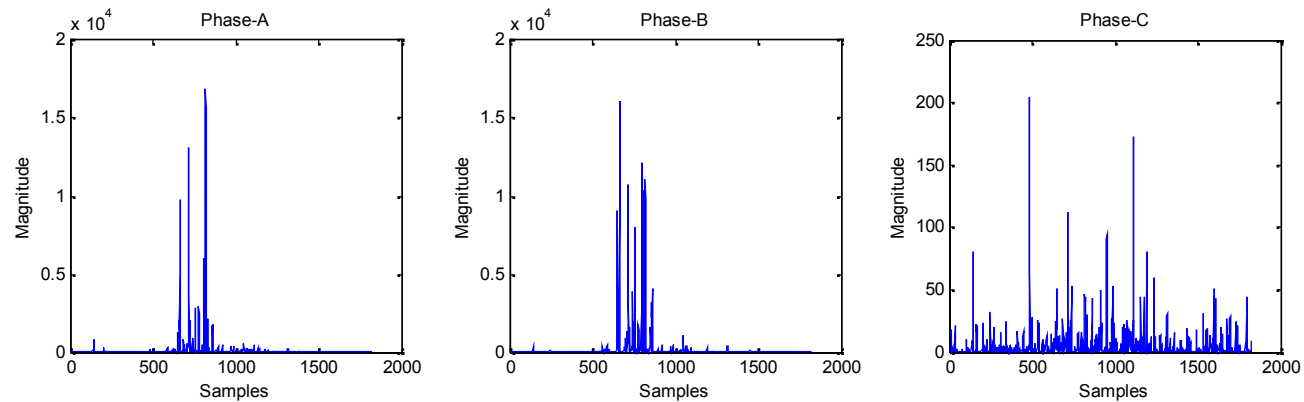

Figure 38. Squared detail-1 coefficients during phase- 'AB-g' fault at $50 \%$ from bus- 1 with $R_{f}=70$ 
Table 9. Relay output for phase-'AB-g' fault at $50 \%$ from bus- 1 with $\mathrm{R}_{\mathrm{f}}=70$

\begin{tabular}{|c|c|c|c|}
\hline \multirow{2}{*}{ Outputs } & A & B & C \\
\cline { 2 - 4 } & $5.0295 * 10^{\wedge} 3$ & $5.8466 * 10^{\wedge} 3$ & 685.5290 \\
\hline $\begin{array}{c}\text { Approximate } \\
\text { Coefficient }\end{array}$ & 135.4043 & 139.2449 & 18.1525 \\
\hline Detail Coefficient & 95.5968 & 96.2319 & 89.0305 \\
\hline Energy & $1.6927 * 10^{\wedge} 4$ & $1.6057 * 10^{\wedge} 4$ & 204.0550 \\
\hline $\begin{array}{c}\text { Squared Detail } \\
\text { coefficients }\end{array}$ & $2.0638^{*} 10^{\wedge} 5$ & $3.0144 * 10^{\wedge} 5$ & $8.1568 * 10^{\wedge} 3$ \\
\hline $\begin{array}{c}\text { Sum of Square of Detail } \\
\text { coefficients }\end{array}$ & & & \\
\hline
\end{tabular}

5.5 Test Results for Fault Inception Time Variation: Simulation studies are carried out to look over the performance of the proposed scheme for fault inception time variation. The three phase current for the period of phase- ${ }^{\circ} \mathrm{C}-\mathrm{g}$ ' fault at $50 \%$ from bus- 1 with FIT $=0.03666$ seconds is shown in Fig. 39. The approximate-1, detail-1 and squared detail- 1 coefficients of phase - A, B and $\mathrm{C}$ for the duration of phase- ' $\mathrm{C}-\mathrm{g}$ ' fault are shown in Fig. 40-42. The process of fault detection using wavelet transform during phase- 'C-g' fault at $50 \%$ from bus- 1 at FIT $=0.03666$ seconds with $R_{f}=0.001$ and $R_{g}=0.001$ can be seen in Fig. 40-42. The performance of the proposed scheme is examined for various values of fault inception time during phase- ' $\mathrm{C}-\mathrm{g}$ ' fault at $50 \%$ from bus-1 with $\mathrm{R}_{\mathrm{f}}=0.001, \mathrm{R}_{\mathrm{g}}=0.001$ with different FIT and the test results for FIT=0.03666 and 0.05666 seconds can be depicted from Table 10 to Table 11. From Table 10-11, it can be definitely seen that the magnitude of sum of square of detail-1 coefficients of faulted phase is larger than the magnitude of sum of square of detail-1 coefficients of un-faulted phase and this illustrates that the proposed wavelet transform based fault detection scheme effectively detects the fault. Based on a variety of test results which can be seen from Table 10-11 it is recognized that the variation in fault inception time has no key effect on the performance of the relay.

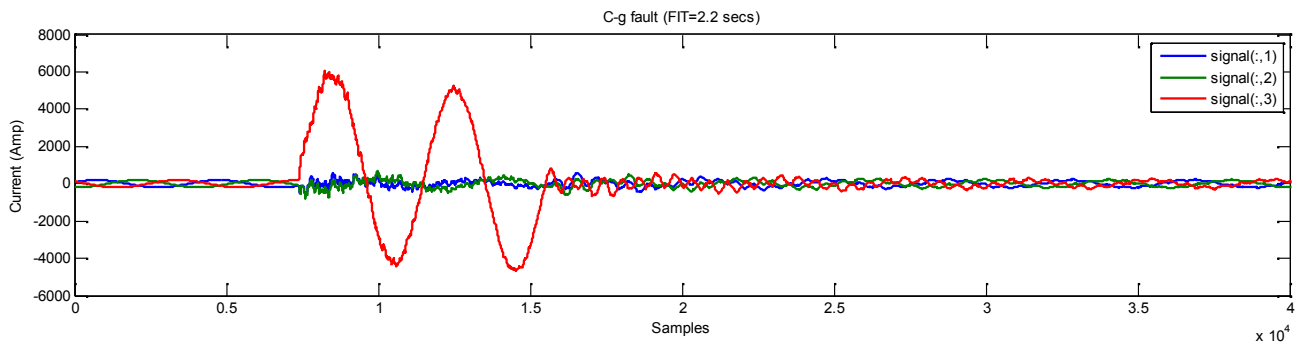

Figure 39. Three phase current during phase- 'C-g' fault at $50 \%$ from bus- 1 with FIT $=0.03666$ seconds
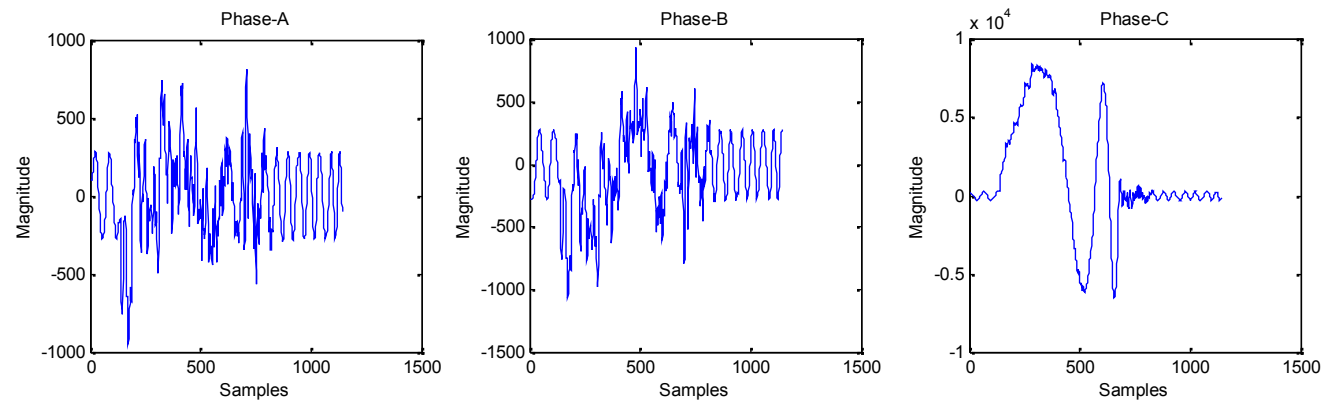

Figure 40. Approximate- 1 coefficients during phase- ' $\mathrm{C}-\mathrm{g}$ ' fault at $50 \%$ from bus- 1 with $\mathrm{FIT}=0.03666$ seconds 

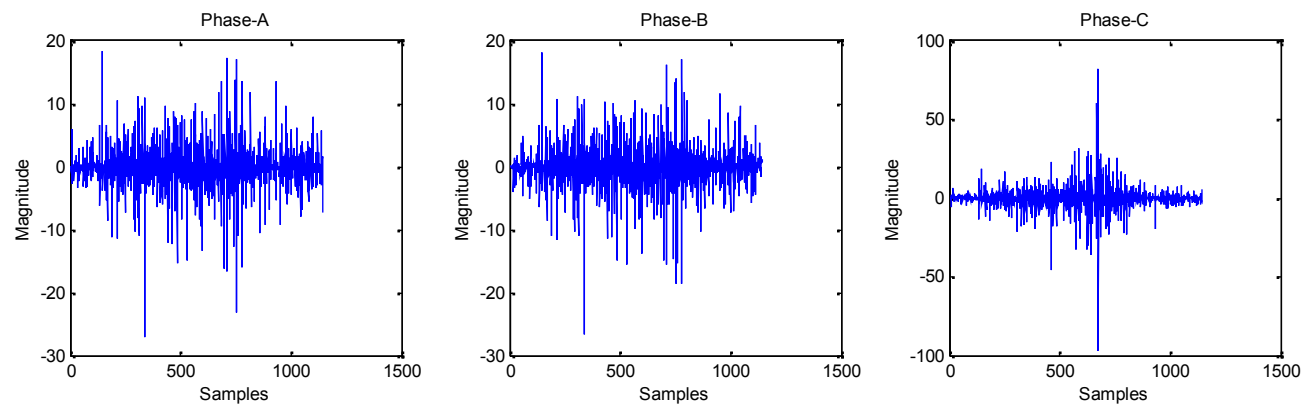

Figure 41. Detail-1 coefficients during phase- ' $\mathrm{C}-\mathrm{g}$ ' fault at $50 \%$ from bus- 1 with FIT $=0.03666$ seconds
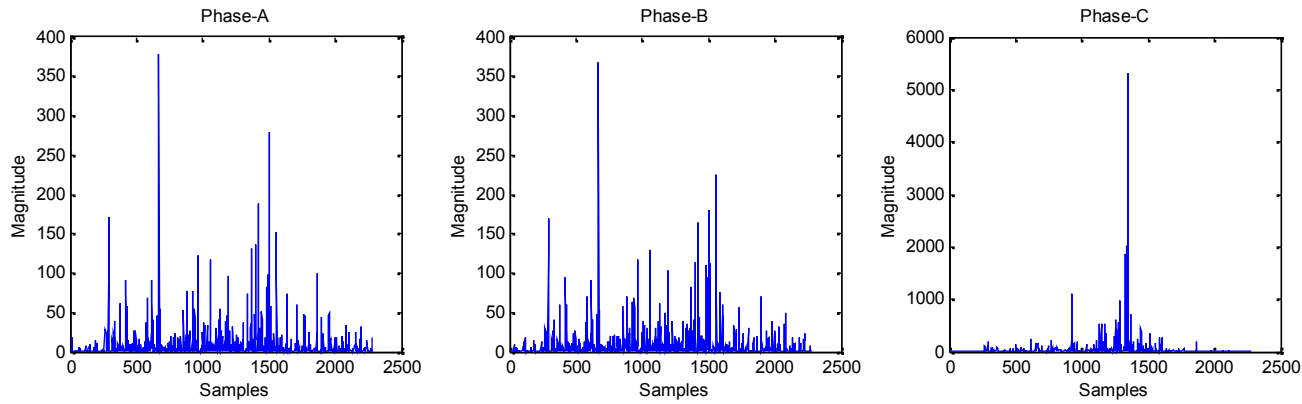

Figure 42. Squared detail-1 coefficients during phase- 'C-g' fault at $50 \%$ from bus- 1 with FIT $=0.03666$ seconds

Table 10. Relay output for phase- ' $\mathrm{C}$-g' fault at $50 \%$ from bus- 1 with FIT $=0.03666$ seconds

\begin{tabular}{|c|c|c|c|}
\hline \multirow{2}{*}{ Outputs } & A & B & C \\
\cline { 2 - 4 } & 809.5998 & 937.1167 & $8.4704 * 10^{\wedge} 3$ \\
\hline $\begin{array}{c}\text { Approximate } \\
\text { Coefficient }\end{array}$ & 18.3515 & 18.2530 & 82.0118 \\
\hline Detail Coefficient & 76.5806 & 83.8924 & 99.7649 \\
\hline Energy & 378.1277 & 367.2886 & $5.3011^{*} 10^{\wedge} 3$ \\
\hline $\begin{array}{c}\text { Squared Detail } \\
\text { coefficients }\end{array}$ & $1.6013 * 10^{\wedge} 4$ & $1.5910^{*} 10^{\wedge} 4$ & $7.7528 * 10^{\wedge} 4$ \\
\hline $\begin{array}{c}\text { Sum of Square of Detail } \\
\text { coefficients }\end{array}$ & & & \\
\hline
\end{tabular}

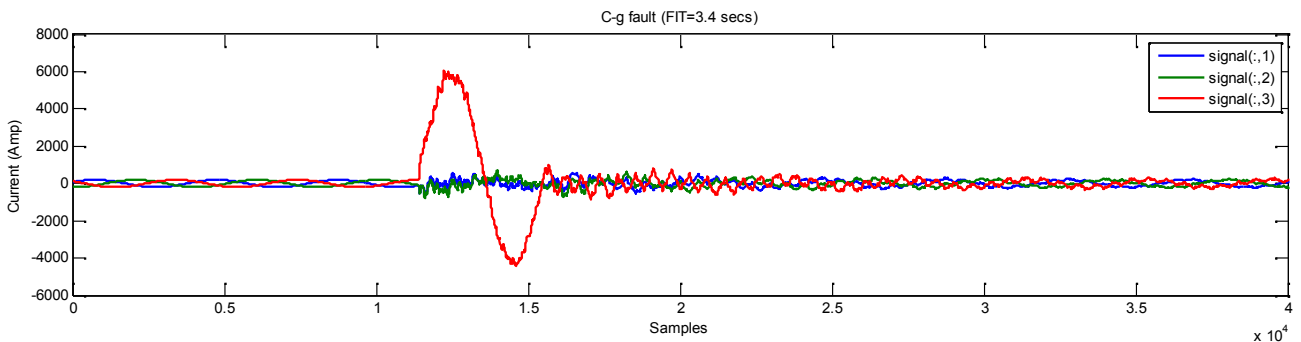

Figure 43. Three phase current during phase- ' $\mathrm{C}$-g' fault at $50 \%$ from bus- 1 with FIT $=0.05666$ seconds 

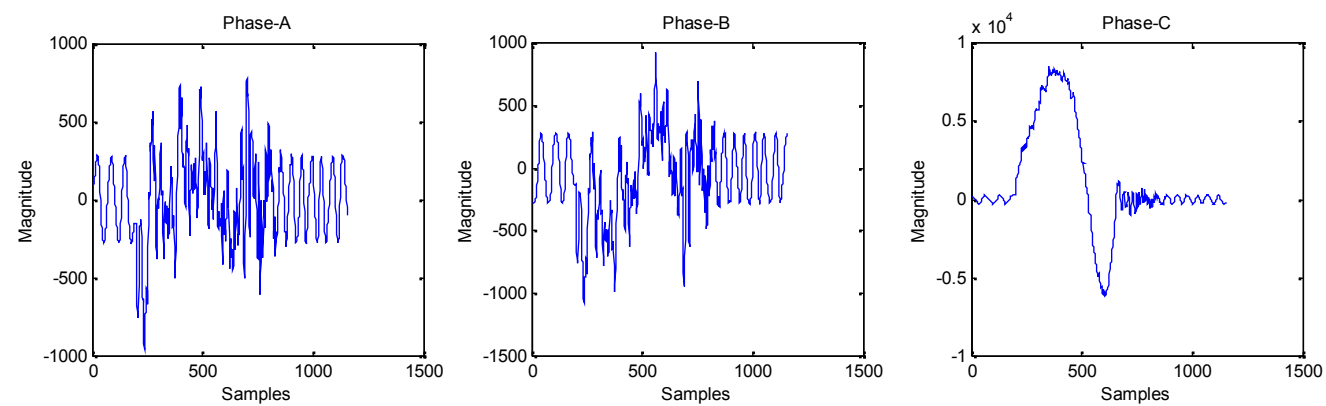

Figure 44. Approximate-1 coefficients during phase- 'C-g' fault at 50\% from bus- 1 with FIT $=0.05666$ seconds
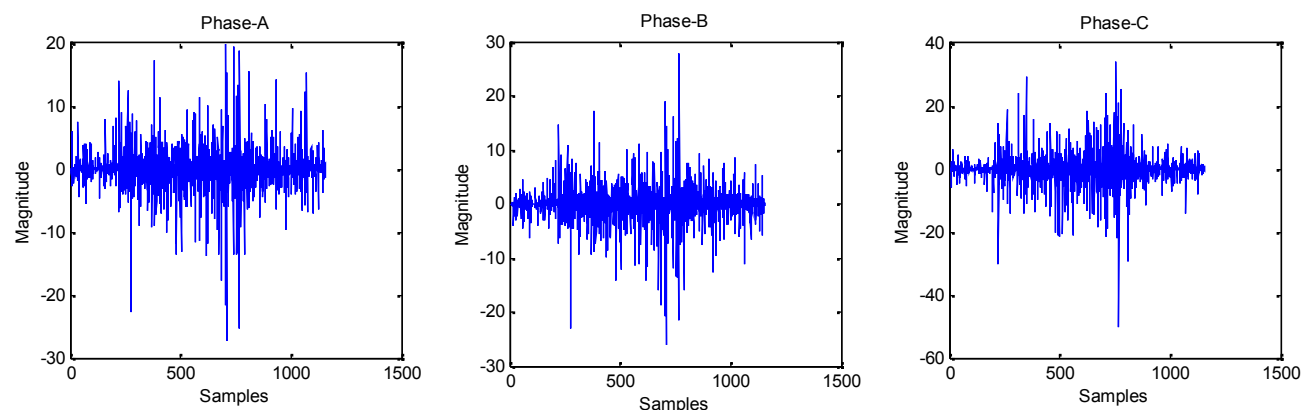

Figure 45. Detail-1 coefficients during phase- 'C-g' fault at 50\% from bus- 1 with FIT $=0.05666$ seconds
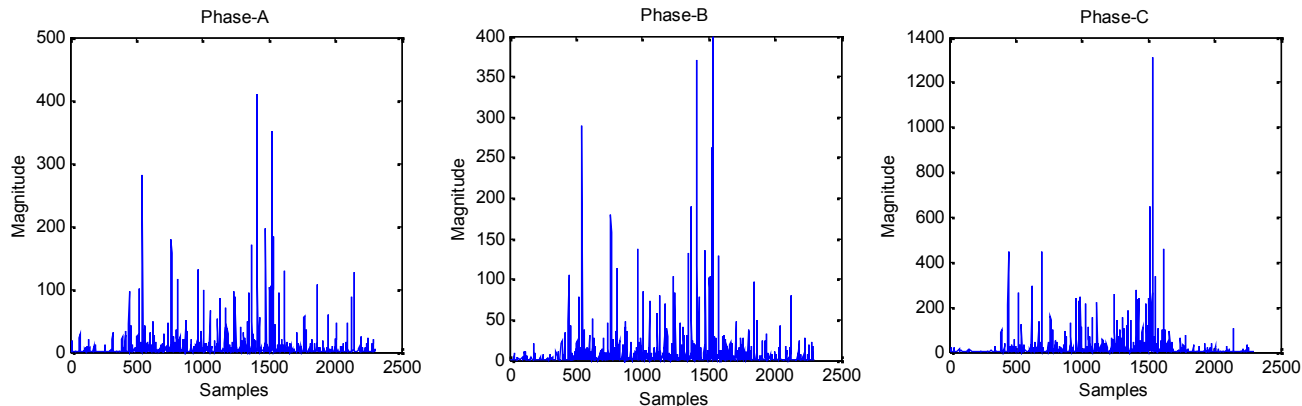

Figure 46. Squared detail- 1 coefficients during phase- 'C-g' fault at $50 \%$ from bus- 1 with FIT $=0.05666$ seconds

Table 11. Relay output for phase- 'C-g' fault at 50\% from bus-1 with FIT=0.05666 seconds

\begin{tabular}{|c|c|c|c|}
\hline \multirow{2}{*}{ Outputs } & A & B & C \\
\cline { 2 - 4 } & 775.8208 & 930.9542 & $8.5128 * 10^{\wedge} 3$ \\
\hline $\begin{array}{c}\text { Approximate } \\
\text { Coefficient }\end{array}$ & 19.9915 & 27.8467 & 34.1329 \\
\hline Detail Coefficient & 77.1393 & 84.2929 & 99.7084 \\
\hline Energy & 409.4042 & 399.7672 & $1.3127 * 10^{\wedge} 3$ \\
\hline $\begin{array}{c}\text { Squared Detail } \\
\text { coefficients }\end{array}$ & $1.81222^{*} 10^{\wedge} 4$ & $1.7990 * 10^{\wedge} 4$ & $3.6882 * 10^{\wedge} 4$ \\
\hline $\begin{array}{c}\text { Sum of Square of Detail } \\
\text { coefficients }\end{array}$ & & & \\
\hline
\end{tabular}

5.6 Test results for ground resistance variation: The performance of the proposed scheme is tested for ground resistance variation. The three phase current for the duration of phase-'BC-g' fault at $50 \%$ from bus- 1 with $\mathrm{R}_{\mathrm{g}}=15$ is shown in Fig. 47. The approximate-1, detail-1 and squared detail-1 coefficients of phase - A, B and C for the duration of phase-'BC-g' fault are shown in 
Fig. 48-50. The procedure of fault detection using wavelet transform during phase- 'BC-g' fault at $50 \%$ from bus-1 at FIT = 0.01667 seconds with $R_{f}=0.001$ and $R_{g}=15$ can be seen in Fig. 48-50. The performance of the proposed scheme is checked up for various values of ground resistances for the duration of phase- 'BC-g' fault at $50 \%$ from bus- 1 with $\mathrm{R}_{\mathrm{f}}=0.001$ and FIT $=$ 0.01667 seconds and the test results for $\mathrm{R}_{\mathrm{g}}=15$ and 65 can be seen from Table 12 to Table 13. From Table 12-13, it can be positively seen that the magnitude of sum of square of detail-1 coefficients of faulted phase is larger than the magnitude of sum of square of detail-1 coefficients of un-faulted phase and this demonstrates that the proposed wavelet transform based fault detection scheme successfully detects the fault. Based on extensive simulation results which can be seen from Table 12 to Table 13, it is established that varying ground resistance has no major effect on the relay performance.

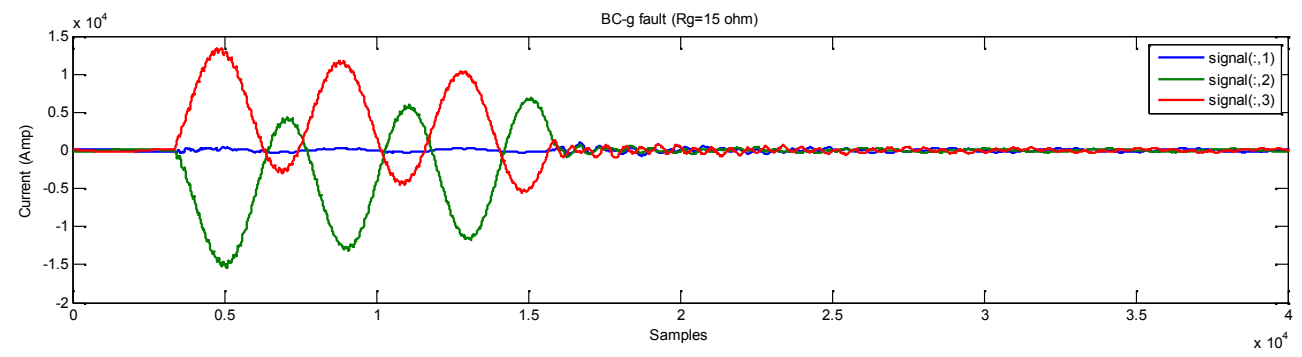

Figure 47. Three phase current during phase-'BC-g' fault at $50 \%$ from bus- 1 with $\mathrm{R}_{\mathrm{g}}=15$
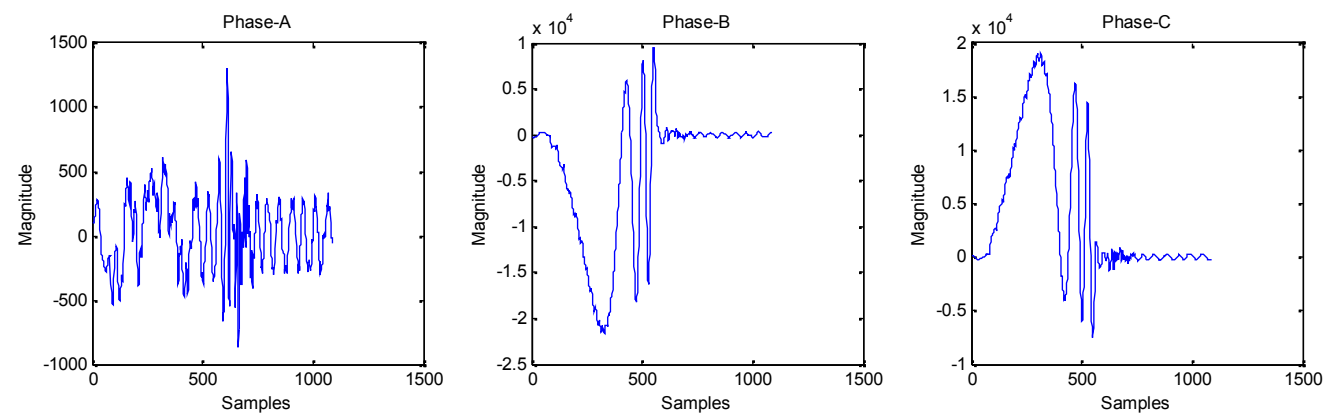

Figure 48. Approximate-1 coefficients during phase- 'BC-g' fault at $50 \%$ from bus-1 with $\mathrm{R}_{\mathrm{g}}=15$
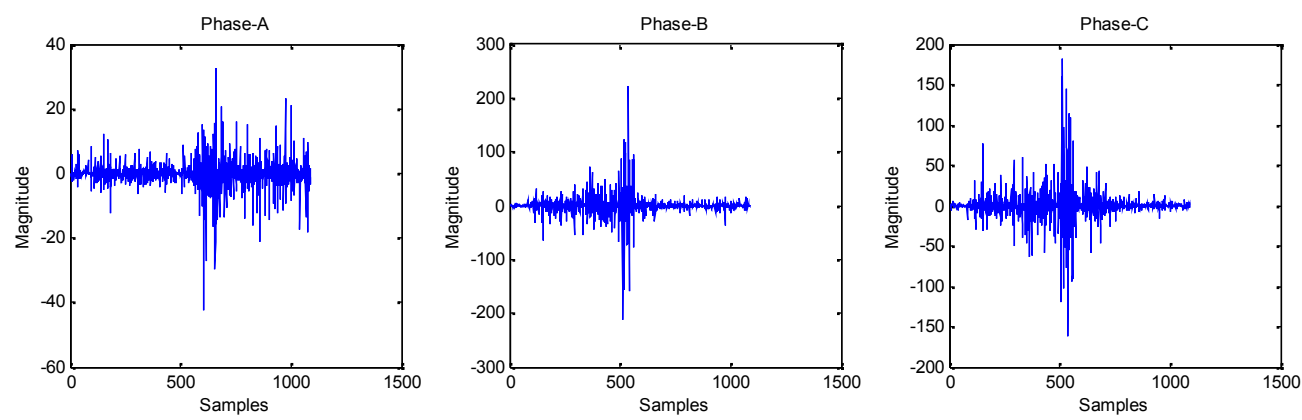

Figure 49. Detail-1 coefficients during phase- 'BC-g' fault at $50 \%$ from bus- 1 with $\mathrm{R}_{\mathrm{g}}=15$
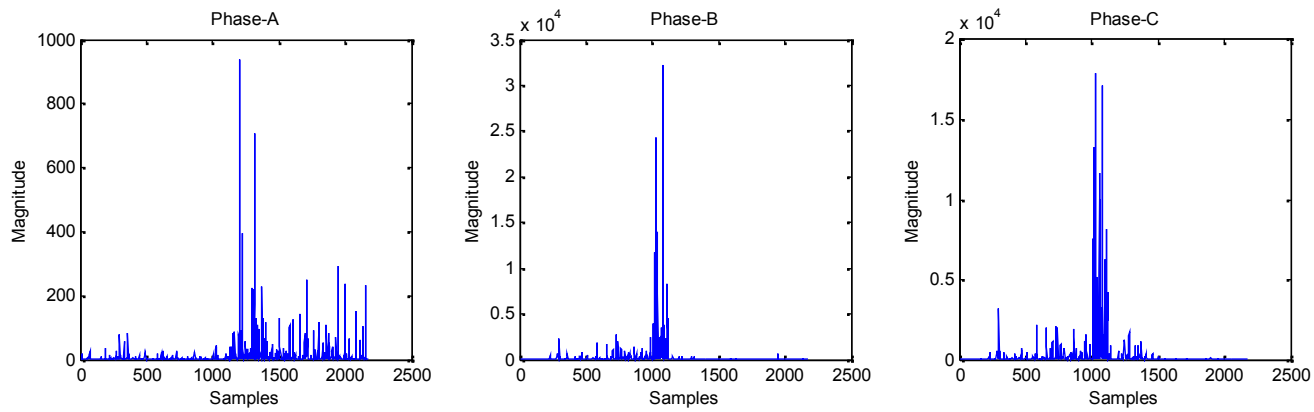

Figure 50. Squared detail-1 coefficients during phase- 'BC-g' fault at 50\% from bus-1 with $\mathrm{R}_{\mathrm{g}}=15$ 
Table 12. Relay output for phase-'BC-g' fault at $50 \%$ from bus- 1 with $\mathrm{Rg}=15$

\begin{tabular}{|c|c|c|c|}
\hline \multirow{2}{*}{ Outputs } & A & B & Chases \\
\cline { 2 - 4 } & $1.3067 * 10^{\wedge} 3$ & $9.5181 * 10^{\wedge} 3$ & $1.9022^{*} 10^{\wedge} 4$ \\
\hline $\begin{array}{c}\text { Approximate } \\
\text { Coefficient }\end{array}$ & 32.6370 & 222.8807 & 182.5869 \\
\hline Detail Coefficient & 69.5537 & 99.0799 & 99.1013 \\
\hline Energy & 936.6530 & $3.2225^{*} 10^{\wedge} 4$ & $1.7894 * 10^{\wedge} 4$ \\
\hline $\begin{array}{c}\text { Squared Detail } \\
\text { coefficients }\end{array}$ & $2.2625^{*} 10^{\wedge} 4$ & $4.4578^{*} 10^{\wedge} 5$ & $3.9707 * 10^{\wedge} 5$ \\
\hline $\begin{array}{c}\text { Sum of Square of Detail } \\
\text { coefficients }\end{array}$ & \multicolumn{2}{|c|}{} \\
\hline
\end{tabular}

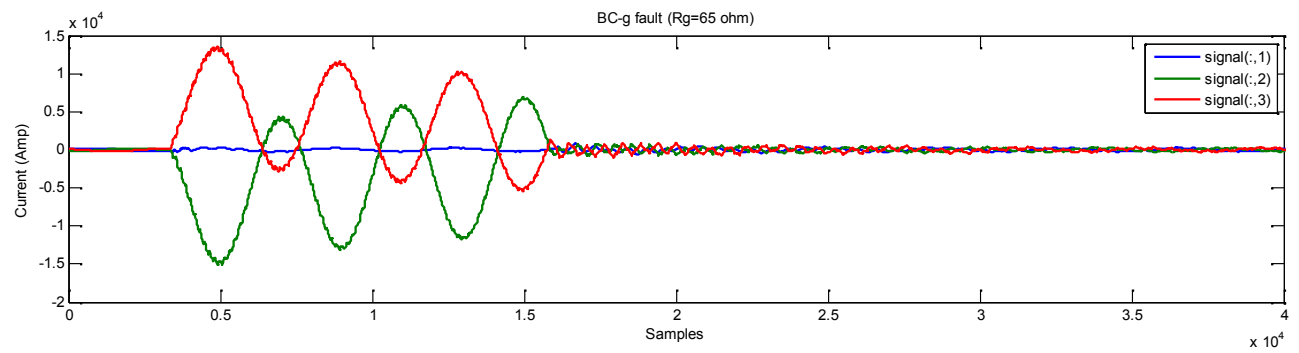

Figure 51. Three phase current during phase-'BC-g' fault at 50\% from bus- 1 with $\mathrm{R}_{\mathrm{g}}=65$
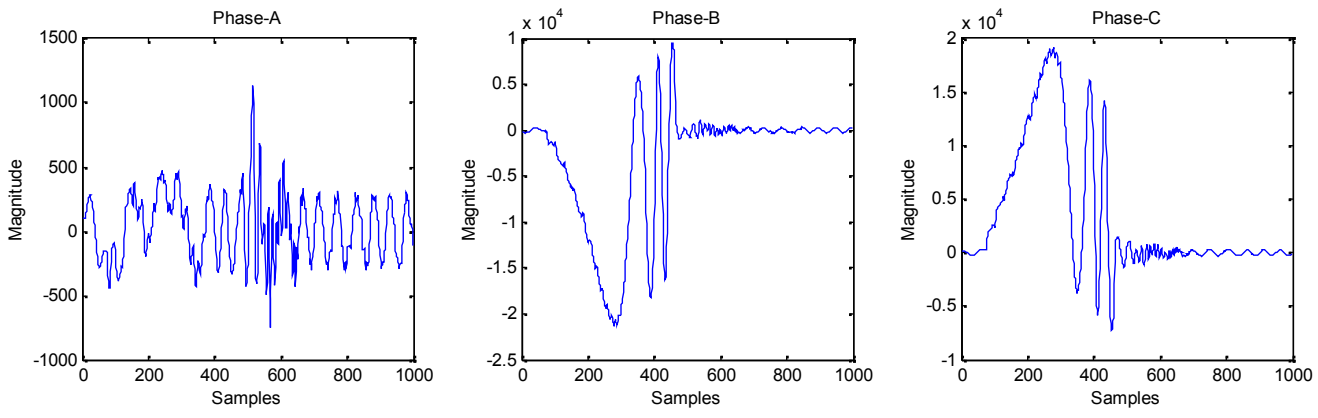

Figure 52. Approximate-1 coefficients during phase- 'BC-g' fault at 50\% from bus- 1 with $\mathrm{R}_{\mathrm{g}}=65$
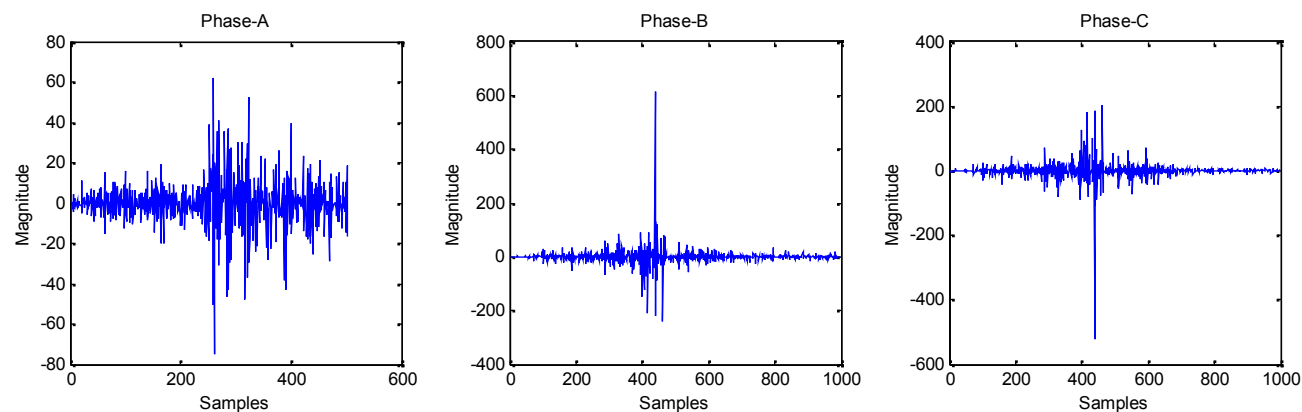

Figure 53. Detail- 1 coefficients during phase- 'BC-g' fault at $50 \%$ from bus- 1 with $\mathrm{R}_{\mathrm{g}}=65$ 

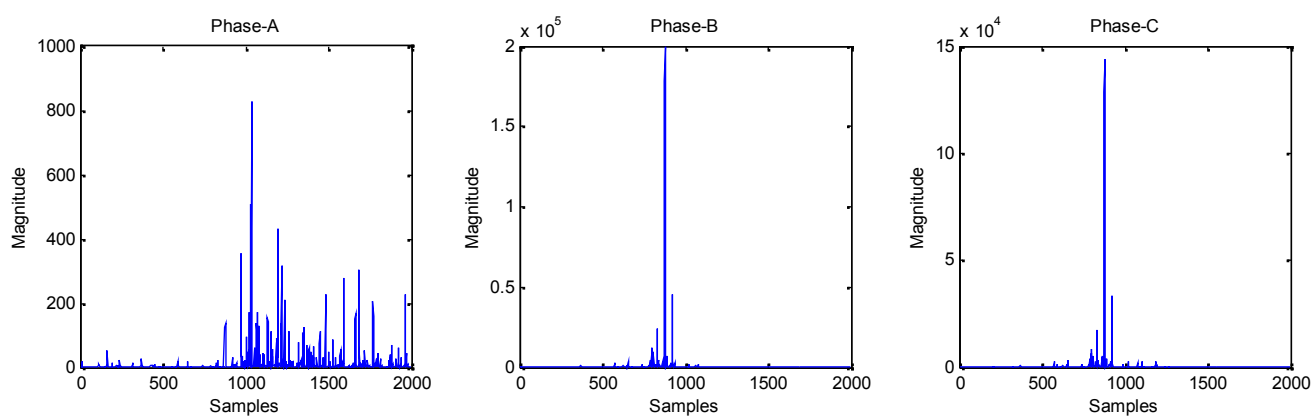

Figure 54. Squared detail-1 coefficients during phase- 'BC-g' fault at 50\% from bus-1 with $\mathrm{R}_{\mathrm{g}}=65$

Table 13. Relay output for phase-'BC-g' fault at 50\% from bus- 1 with $\mathrm{Rg}=65$

\begin{tabular}{|c|c|c|c|}
\hline \multirow{2}{*}{ Outputs } & A & Phases & C \\
\cline { 2 - 4 } & $1.1283^{*} 10^{\wedge} 3$ & $9.5243^{*} 10^{\wedge} 3$ & $1.9129^{*} 10^{\wedge} 4$ \\
\hline $\begin{array}{c}\text { Approximate } \\
\text { Coefficient }\end{array}$ & 33.1386 & 614.7625 & 204.8328 \\
\hline $\begin{array}{c}\text { Detail Coefficient } \\
\text { Energy }\end{array}$ & 71.3588 & 98.0871 & 98.4516 \\
\hline $\begin{array}{c}\text { Squared Detail } \\
\text { coefficients }\end{array}$ & 826.4800 & $1.9943 * 10^{\wedge} 5$ & $1.4386^{*} 10^{\wedge} 5$ \\
\hline $\begin{array}{c}\text { Sum of Square of Detail } \\
\text { coefficients }\end{array}$ & $2.1388^{*} 10^{\wedge} 4$ & $8.7587^{*} 10^{\wedge} 5$ & $6.8390^{*} 10^{\wedge} 5$ \\
\hline
\end{tabular}

\section{Conclusion}

Proposed wavelet transform based fault detector for the protection of series capacitor compensated three phase transmission line is established to be very successful under numerous circumstances of fault. Three phase fault current has been processed using 'db4' wavelet. The performance of proposed wavelet transform based fault detector is not affected by variation in fault parameters like fault inception time, fault resistance, fault type, fault location and ground resistance. The proposed fault detector has been found $100 \%$ accurate for detecting the fault and identifying the faulty phase. The future extension of this technique will be on fault detection, classification and location estimation of FACTS (flexible AC transmission systems) compensated three phase double and six phase transmission lines.

\section{References}

Abdelgayed T. S., Morsi W. G., and Sidhu T. S., 2016. A New Harmony search approach for optimal wavelets applied to fault classification, IEEE Transactions on Smart Grid, Vol. 9, No. 2, pp. 521-529.

Bhongade S. and Golhani S., 2016. HIF detection using wavelet transform, travelling wave, and support vector machine, Proceeding of the IEEE International Conference on Electrical Power and Energy Systems, pp. 151-156.

Bhalja B. and Maheshwari R. P., 2006. Wavelet transform based differential protection scheme for tapped transmission line, Proceeding of the IEEE International Conference on Industrial Technology, pp. 1004-1008.

Chen J. and Aggarwal R. K., 2012. A new approach to EHV transmission line fault classification and fault detection based on the wavelet transform and artificial intelligence, Proceeding of the IEEE Power and Energy Society General Meeting, pp. 1-8.

Cheong W. J. and Aggarwal R. K., 2004. A novel fault location technique based on current signals only for thyristor controlled series compensated transmission lines using wavelet analysis and self-organizing map neural networks, Proceeding of the $8^{\text {th }}$ IEE International Conference on Developments in Power System Protection, pp. 224-227.

Das D., Singh N. K. and Sinha A. K., 2006. A comparison of Fourier transform and wavelet transform methods for detection and classification of faults on transmission lines, Proceeding of the IEEE Power India Conference.

Jain A., Thoke A. S., Patel R. N. and Koley E., 2010. Inter-circuit and cross-country fault detection and classification using artificial neural network, Proceeding of the IEEE Annual India Conference, pp. 1-4. 
Jena P. and Pradhan A. K., 2013. Directional relaying in the presence of a thyristor-controlled series capacitor, IEEE Transactions on Power Delivery, Vol. 28, No. 2, pp. 628-636.

Kale V. S., Bhide S. R., and Bedekar P. P., 2009. Faulted phase selection on double circuit transmission line using wavelet transform and neural network, Proceeding of the IEEE International Conference on Power Systems, pp. 1-6.

Khorashadi Z. H., 2004. Artificial neural network approach to fault classification for double circuit transmission lines, Proceeding of the IEEE/PES Transmission and Distribution Conference and Exposition, pp. 859-862.

Kang N., Chen J., and Liao Y., 2015. A fault-location algorithm for series-compensated double-circuit transmission lines using the distributed parameter line model, IEEE Transactions on Power Delivery, Vol. 30, No. 1, pp. 360-367.

Liang F. and Jeyasurya B., 2004. Transmission line distance protection using wavelet transform algorithm, IEEE Transactions on Power Delivery, Vol. 19, No. 2, pp. 545-553.

Mishra M. and Rout P. K., 2018. Detection and classification of micro-grid faults based on Hilbert huang transform and machine learning techniques, IET Generation, Transmission, and Distribution, Vol. 12, No. 2, pp. 388-397.

Moravej Z., Movahhedneya M., Radman G., and Pazoki M., 2015. Effective fault location technique in three terminal transmission line using Hilbert and DWT, Proceeding of the IEEE International Conference on Electro/Information Technology, pp. 170176.

Rangari C. and Yadav A., 2017. A hybrid wavelet singular entropy and fuzzy system based fault detection and classification on distribution line with distributed generation, Proceeding of the IEEE $2^{\text {nd }}$ International Conference on Recent Trends in Electronics, Information and Communication Technology, pp. 1473-1477.

Rawal P. D. and Pandya A. S., 2016. Accurate fault classification in series compensated multi-terminal extra high voltage transmission line using probabilistic neural network, Proceeding of the IEEE International Conference on Electrical, Electronics, and Optimization Techniques, pp. 1550-1554.

Saha B., Patel B., and Bera P., 2016. DWT and BPNN based fault detection, classification and estimation of location of HVAC transmission line, Proceeding of the IEEE International Conference on Intelligent Control Power and Instrumentation, pp. 174-178.

Swetapadma A. and Yadav A., 2015. Time domain complete protection scheme for parallel transmission lines, Ain Shams Engineering Journal, Vol. 7, No. 1, pp. 169-183.

Swetapadma A. and Yadav A., 2018. An artificial neural network based solution to locate the multi location faults in double circuit series capacitor compensated transmission lines, International Transactions on Electrical Energy System, pp. 1-20.

Shukla S.K., Koley E. and Ghosh S., 2018. A hybrid wavelet-APSO-ANN based protection scheme for six phase transmission line with real time validation, Neural Computing and Applications.

Xie F., Haddad A., and Griffiths H., 2013. Single-ended fault location method based on wavelet theory: application to a doublecircuit transmission line, Proceeding of the IEEE 48 ${ }^{\text {th }}$ International Universities Power Engineering Conference, pp. 1-6.

Yadav A., 2012. Comparison of single and modular ANN based fault detector and classifier for double circuit transmission lines, International Journal of Engineering, Science and Technology, Vol. 4, No. 2, pp. 122-136.

\section{Biographical notes}

Gaurav Kapoor received B.E. in Electrical Engineering from University of Rajasthan, Jaipur, India and M. Tech. in Power System specialization from University College of Engineering, Rajasthan Technical University, Kota, India in 2011 and 2014, respectively. He is an Assistant Professor in the Department of Electrical Engineering, Modi Institute of Technology Kota, India. His research interests include power system digital protection.

Received June 2018

Accepted October 2018

Final acceptance in revised form October 2018 